\title{
A Systems Biology Overview on Human Diabetic Nephropathy: From Genetic Susceptibility to Post-Transcriptional and Post-Translational Modifications
}

\author{
Francesca Conserva, ${ }^{1,2}$ Loreto Gesualdo, ${ }^{1}$ and Massimo Papale ${ }^{3}$ \\ ${ }^{1}$ Division of Nephrology, Department of Emergency and Organ Transplantation, University of Bari, 70124 Bari, Italy \\ ${ }^{2}$ Division of Cardiology and Cardiac Rehabilitation, "S. Maugeri" Foundation, IRCCS, Institute of Cassano Murge, \\ 70020 Cassano delle Murge, Italy \\ ${ }^{3}$ Molecular Medicine Center, Section of Nephrology, Department of Medical and Surgical Sciences, University of Foggia, \\ 71122 Foggia, Italy
}

Correspondence should be addressed to Loreto Gesualdo; loreto.gesualdo@uniba.it

Received 29 May 2015; Revised 16 August 2015; Accepted 10 September 2015

Academic Editor: Shirong Zheng

Copyright ( 12016 Francesca Conserva et al. This is an open access article distributed under the Creative Commons Attribution License, which permits unrestricted use, distribution, and reproduction in any medium, provided the original work is properly cited.

\begin{abstract}
Diabetic nephropathy (DN), a microvascular complication occurring in approximately $20-40 \%$ of patients with type 2 diabetes mellitus (T2DM), is characterized by the progressive impairment of glomerular filtration and the development of KimmelstielWilson lesions leading to end-stage renal failure (ESRD). The causes and molecular mechanisms mediating the onset of T2DM chronic complications are yet sketchy and it is not clear why disease progression occurs only in some patients. We performed a systematic analysis of the most relevant studies investigating genetic susceptibility and specific transcriptomic, epigenetic, proteomic, and metabolomic patterns in order to summarize the most significant traits associated with the disease onset and progression. The picture that emerges is complex and fascinating as it includes the regulation/dysregulation of numerous biological processes, converging toward the activation of inflammatory processes, oxidative stress, remodeling of cellular function and morphology, and disturbance of metabolic pathways. The growing interest in the characterization of protein post-translational modifications and the importance of handling large datasets using a systems biology approach are also discussed.
\end{abstract}

\section{Introduction}

DN is an endemic complication of diabetes and the first cause of ESRD worldwide. The contributing causes of DN pathogenesis and progression are still poorly understood but chronic hyperglycemia and high blood pressure represent the main risk factors for disease onset.

Hemodynamic and Biochemical Background. In the early stages of DN, high systemic blood pressure usually determines an increase of the intraglomerular pressure and glomerular filtration rate (GFR) which results in glomerular hyperfiltration [1]. From the biochemical point of view, hyperglycemia per se sustains the accumulation of advanced glycation end products (AGEs), altering the electronegativity of the cell; additionally AGEs bind proteins of the extracellular matrix (ECM) inhibiting their degradation. AGEs accumulation can induce an increased production of reactive oxygen species (ROS) and a transcriptional activation of different proinflammatory and profibrotic molecules, including TGF-beta $[2,3]$. The high glucose-mediated induction of TGF-beta and the central role of this growth factor in DN progression represent the few defining constants in the pathogenesis of DN [4].

Clinical and Histological Hallmarks of DN. The earliest clinical signs of DN include a slight but persistent urinary excretion of albumin (microalbuminuria) and a temporary increase of the glomerular filtration rate (GFR). These clinical signs, along with the presence of hyperglycemia, are often considered sufficient indicators of DN $[5,6]$. Today, extensive evidence shows that $\mathrm{DN}$ is not the only type of renal damage that can be 
found in diabetic patients $[7,8]$ and kidney biopsy, although highly invasive, remains the diagnostic gold standard. The histological hallmarks of DN include hyperproliferation of the mesangial cells, thickening of the glomerular basement membrane (GBM), podocyte effacement, tubulointerstitial fibrosis, and nodular accumulations of ECM (KimmelstielWilson lesions) in the glomerulus [9].

Given the high prevalence of type 2 diabetes (T2D) and the diagnostic limitations currently associated with kidney biopsy, there is an impending need for new, accurate, and easily accessible biomarkers of disease.

In this review we will try to outline a system biology overview on DN by recapitulating the main annotations obtained at different levels of molecular investigation. Only those studies investigating human samples will be described; the murine models of DN in fact, although undergoing albuminuria, mesangial expansion, and podocyte loss, do not develop severe glomerulosclerosis and tubulointerstitial fibrosis [10]. Also, as substantial differences exist in the etiology and prevalence of type 1 and type $2 \mathrm{DN}$, the articles discussed in this paper apply to DN secondary to type 2 diabetes (T2DN). As an exception, works describing biomarkers of kidney damage in T1D that have been further validated in T2DM and vice versa and those reporting potential prognostic biomarkers, because of their particular importance in predicting the progression of renal damage, have been also discussed in the present work. All the annotations discussed in this review are also listed in Tables 1, 2, 3, 4, and 5, categorized according to whether they summarize the genetic and transcriptomic signature of coding or noncoding RNA molecules and the epigenetic proteomic and metabolomic markers, respectively.

\section{Genetic Profiling of DN}

Genetic variation is present under different forms in the human genome, ranging from single nucleotide polymorphisms (SNPs) to large, structural, chromosomal rearrangements. Today we know that genetic variation infers disease susceptibility and collective effort aims at identifying the precise loci for DN susceptibility. Different methodological strategies can be used to characterize the genetic risk for a disease, either targeted or genome-wide, according to whether a priori hypothesis of the candidate regions for disease susceptibility exists. In genome-wide association studies (GWAS), for instance, the whole genome is screened for new, previously uncharacterized single nucleotide polymorphisms (SNPs).

Prior to the development of the modern high-throughput technologies such as chip-based microarray analysis and next-generation sequencing, the inheritance of disease susceptibility was investigated through genetic linkage in families. Basically, individuals within the same families were sequenced for a collection of genetic SNPs in order to identify those SNPs segregating with the disease. This approach led to the identification of many variants responsible for disease susceptibility but it proved mostly suitable for the study of single gene disorders. For complex, common complications like T2D in fact, progression is very likely driven by multiple alleles simultaneously, each having a small correlation to disease progression if inherited individually. This implies that a big population needs to be genotyped in order to detect the common variants responsible for the increased genetic risk.

In the field of $\mathrm{DN}$, there is extensive evidence for genetic contribution to disease susceptibility. In 1989, Seaquist et al. showed that diabetic siblings of patients with DN were more at risk for developing DN compared to diabetic siblings of diabetic patients without proteinuria [99]; epidemiologic studies also indicate that the prevalence of $\mathrm{DN}$ varies among ethnic groups [100]. These observations, along with the consideration that only a subset of patients with diabetes develops DN, drove the search for the genetic determinants of DN susceptibility.

One of the most consistent annotations in the field is probably the genetic variation on chromosome 18. In 2002, a family-based linkage analysis performed in T2DN Turkish families and affected sibling pairs of Pima Indians reported a strong evidence for the localization of a DN susceptibility locus mapping to chromosome 18q22.3-23 [12]. Researchers were not able to pinpoint the precise susceptibility gene but the same locus was also detected in a T2DN African American population [11]. Later studies on chromosome 18 led to the identification of a susceptibility marker within the carnosine dipeptidase 1 (CNDP1) gene, and it was also described how the shortest allelic form of the CNDP1 gene was more common in the absence of nephropathy [15]. The CNDP1 gene encodes the secreted enzyme serum carnosinase that degrades carnosine, a protein controlling the formation of AGE molecules [101]. As previously discussed, AGE's accumulation is a phenotypic sign of DN. Similar results were obtained in a meta-analysis study when investigating a multiethnic population with T2D-ESRD [16]; a recently published meta-analysis confirmed the association of the carnosinase D18S880 microsatellite polymorphism with DN susceptibility in a T2D Caucasian population although no significant association with T1DN could be found [17].

In a very recent candidate-gene driven study, Palmer et al. performed a genotyping of several SNPs across $22 \mathrm{DN}$ candidate genes in a large cohort of African Americans with T2D and ESRD. After adjustment for the APOL1 G1/G2 alleles, known to be associated with nondiabetic ESRD in this population, the most significant signals were observed downstream of the CNDP1 gene, at chimerin 2 (CHN2) locus and within angiotensin II receptor type 1 (AGTR1) gene [13]. In another work, to investigate the impact of oxidative stress on disease initiation, the polymorphic variants of 7 genes involved in the antioxidant defense were evaluated: SOD2, p22 phox, CAT, MPO, GSTP1, GSTT1, and GSTM1. Despite the commonly recognized link between oxidative stress and diabetes, authors claim that no association could be found in Caucasian T2D patients [102].

In one of the first DN genome-wide genotyping studies, authors reported the engulfment and cell motility 1 (ELMO1) gene on chromosome $7 \mathrm{p}$ as a likely candidate for disease susceptibility in a Japanese patients cohort with T2D [19]. In a cellular system engineered to overexpress ELMO1, they furthermore observed increased expression of extracellular matrix (ECM) protein genes and decreased expression 
TABLE 1: Genetic markers. Collection of significant genetic markers, listed alphabetically.

\begin{tabular}{|c|c|c|c|c|c|c|}
\hline Nearest gene(s) & Variant & Ethnicity & Diabetes type & Assay type & $\begin{array}{c}\text { Potential } \\
\text { value of } \\
\text { biomarker }\end{array}$ & References \\
\hline $18 \mathrm{q}$ & D18S1364 & African American & $\mathrm{T} 2 \mathrm{D}$ & $\begin{array}{l}\text { Linkage } \\
\text { analysis }\end{array}$ & Diagnostic & {$[11]$} \\
\hline $18 q 22.3-23$ & D18S43/D18S50 & Turkish & $\mathrm{T} 2 \mathrm{D}$ & $\begin{array}{l}\text { Linkage } \\
\text { analysis }\end{array}$ & Diagnostic & {$[12]$} \\
\hline $18 q 22.3-23$ & D18S43/D18S50 & Pima Indians & $\mathrm{T} 2 \mathrm{D}$ & $\begin{array}{l}\text { Linkage } \\
\text { analysis }\end{array}$ & Diagnostic & {$[12]$} \\
\hline $7 \mathrm{p}$ & D7S3051 & African American & $\mathrm{T} 2 \mathrm{D}$ & $\begin{array}{l}\text { Linkage } \\
\text { analysis }\end{array}$ & Diagnostic & [11] \\
\hline AGTR1 & rs12695897 & African American & $\mathrm{T} 2 \mathrm{D}$ & $\begin{array}{l}\text { Candidate } \\
\text { based } \\
\text { genotyping }\end{array}$ & Diagnostic & {$[13]$} \\
\hline APOL3 & rs16996381 & African American & $\mathrm{T} 2 \mathrm{D}$ & GWAS & Diagnostic & {$[14]$} \\
\hline AUH & rs773506 & African American & $\mathrm{T} 2 \mathrm{D}$ & GWAS & Diagnostic & {$[14]$} \\
\hline C12orf66/TMEM5 & rs11175885 & African American & $\mathrm{T} 2 \mathrm{D}$ & GWAS & Diagnostic & {$[14]$} \\
\hline C6orf167 & rs3822908 & African American & $\mathrm{T} 2 \mathrm{D}$ & GWAS & Diagnostic & {$[14]$} \\
\hline C6orf191/ARHGAP18 & rs208865 & African American & $\mathrm{T} 2 \mathrm{D}$ & GWAS & Diagnostic & {$[14]$} \\
\hline CHN2 & rs2057737 & African American & $\mathrm{T} 2 \mathrm{D}$ & $\begin{array}{c}\text { Candidate } \\
\text { based } \\
\text { genotyping }\end{array}$ & Diagnostic & {$[13]$} \\
\hline $\mathrm{CHN} 2$ & rs3729621 & African American & $\mathrm{T} 2 \mathrm{D}$ & $\begin{array}{c}\text { Candidate } \\
\text { based } \\
\text { genotyping }\end{array}$ & Diagnostic & {$[13]$} \\
\hline CHN2 & rs3793313 & African American & $\mathrm{T} 2 \mathrm{D}$ & $\begin{array}{c}\text { Candidate } \\
\text { based } \\
\text { genotyping }\end{array}$ & Diagnostic & {$[13]$} \\
\hline CNDP1 & D18S880 & European & $\mathrm{T} 1 \mathrm{D} / \mathrm{T} 2 \mathrm{D}$ & $\begin{array}{l}\text { Candidate } \\
\text { based } \\
\text { genotyping }\end{array}$ & Diagnostic & {$[15]$} \\
\hline CNDP1 & D18S880 & Multiethnic & $\mathrm{T} 2 \mathrm{D}$ & Meta-analysis & Diagnostic & {$[16]$} \\
\hline CNDP1 & rs4892249 & African American & $\mathrm{T} 2 \mathrm{D}$ & $\begin{array}{c}\text { Candidate } \\
\text { based } \\
\text { genotyping }\end{array}$ & Diagnostic & [13] \\
\hline CNDP1 & rs6566815 & African American & $\mathrm{T} 2 \mathrm{D}$ & $\begin{array}{l}\text { Candidate } \\
\text { based } \\
\text { genotyping }\end{array}$ & Diagnostic & [13] \\
\hline CNDP1 & D18S880 & Caucasian & $\mathrm{T} 2 \mathrm{D}$ & Meta-analysis & Diagnostic & {$[17]$} \\
\hline ELMO1 & rs741301 & Asian & $\mathrm{T} 2 \mathrm{D}$ & Meta-analysis & Diagnostic & {$[16]$} \\
\hline ELMO1 & rs11769038 & Caucasian & T1D & GWAS & Diagnostic & {$[18]$} \\
\hline ELMO1 & rs1882080 & Caucasian & $\mathrm{T} 1 \mathrm{D}$ & GWAS & Diagnostic & {$[18]$} \\
\hline ELMO1 & rs2041801 & Caucasian & $\mathrm{T} 1 \mathrm{D}$ & GWAS & Diagnostic & {$[18]$} \\
\hline ELMO1 & rs7785934 & Caucasian & T1D & GWAS & Diagnostic & {$[18]$} \\
\hline ELMO1 & Intron $18+9170(\mathrm{~A} / \mathrm{G})$ & Japanese & $\mathrm{T} 2 \mathrm{D}$ & GWAS & Diagnostic & [19] \\
\hline FRMD3 & rs1535753 & African American & $\mathrm{T} 2 \mathrm{D}$ & GWAS & Diagnostic & {$[20]$} \\
\hline FRMD3 & rs2378658 & African American & $\mathrm{T} 2 \mathrm{D}$ & GWAS & Diagnostic & {$[20]$} \\
\hline FRMD3 & rs942278 & African American & $\mathrm{T} 2 \mathrm{D}$ & GWAS & Diagnostic & {$[20]$} \\
\hline FRMD3 & rs942280 & African American & $\mathrm{T} 2 \mathrm{D}$ & GWAS & Diagnostic & {$[20]$} \\
\hline FRMD3 & rs942283 & African American & $\mathrm{T} 2 \mathrm{D}$ & GWAS & Diagnostic & {$[20]$} \\
\hline
\end{tabular}


TABle 1: Continued.

\begin{tabular}{|c|c|c|c|c|c|c|}
\hline Nearest gene(s) & Variant & Ethnicity & Diabetes type & Assay type & $\begin{array}{c}\text { Potential } \\
\text { value of } \\
\text { biomarker }\end{array}$ & References \\
\hline FRMD3 & rs1888747 & European & $\mathrm{T} 2 \mathrm{D}$ & $\begin{array}{c}\text { Candidate } \\
\text { based } \\
\text { genotyping }\end{array}$ & Diagnostic & {$[21]$} \\
\hline GRIK2 & rs7760831 & African American & $\mathrm{T} 2 \mathrm{D}$ & GWAS & Diagnostic & [14] \\
\hline GRIP1/CAND1 & rs11176482 & African American & $\mathrm{T} 2 \mathrm{D}$ & GWAS & Diagnostic & {$[14]$} \\
\hline GRIP1/CAND1 & rs2904532 & African American & $\mathrm{T} 2 \mathrm{D}$ & GWAS & Diagnostic & {$[14]$} \\
\hline LIMK2 & rs2106294 & African American & $\mathrm{T} 2 \mathrm{D}$ & GWAS & Diagnostic & [14] \\
\hline LIMK2 & rs4820043 & African American & $\mathrm{T} 2 \mathrm{D}$ & GWAS & Diagnostic & {$[14]$} \\
\hline MSRB3/HMGA2 & rs2358944 & African American & $\mathrm{T} 2 \mathrm{D}$ & GWAS & Diagnostic & {$[14]$} \\
\hline MYH9 & rs735853 & African American & $\mathrm{T} 2 \mathrm{D}$ & GWAS & Diagnostic & {$[14]$} \\
\hline NAV3 & rs12302041 & African American & $\mathrm{T} 2 \mathrm{D}$ & GWAS & Diagnostic & {$[14]$} \\
\hline ND & rs1978243 & African American & $\mathrm{T} 2 \mathrm{D}$ & GWAS & Diagnostic & {$[14]$} \\
\hline ND & rs4260465 & African American & $\mathrm{T} 2 \mathrm{D}$ & GWAS & Diagnostic & {$[14]$} \\
\hline ND & rs7697691 & African American & $\mathrm{T} 2 \mathrm{D}$ & GWAS & Diagnostic & {$[14]$} \\
\hline OR2L13 & rs10888287 & African American & $\mathrm{T} 2 \mathrm{D}$ & GWAS & Diagnostic & {$[14]$} \\
\hline PVT1 & rs2648875 & Pima Indians & $\mathrm{T} 2 \mathrm{D}$ & GWAS & Diagnostic & {$[22]$} \\
\hline PVT1 & rs13447075 & European & $\mathrm{T} 1 \mathrm{D}$ & $\begin{array}{l}\text { Candidate } \\
\text { based } \\
\text { genotyping }\end{array}$ & Diagnostic & {$[23]$} \\
\hline RNF185 & rs1034589 & African American & $\mathrm{T} 2 \mathrm{D}$ & GWAS & Diagnostic & {$[14]$} \\
\hline RPS12 & rs7769051 & African American & $\mathrm{T} 2 \mathrm{D}$ & GWAS & Diagnostic & {$[14]$} \\
\hline RPS12 & rs9493454 & African American & $\mathrm{T} 2 \mathrm{D}$ & GWAS & Diagnostic & {$[14]$} \\
\hline SASH1 & rs6930576 & African American & $\mathrm{T} 2 \mathrm{D}$ & GWAS & Diagnostic & {$[14]$} \\
\hline SFI1 & rs5749286 & African American & $\mathrm{T} 2 \mathrm{D}$ & GWAS & Diagnostic & {$[14]$} \\
\hline SLC10A7/LSM6 & rs891382 & African American & $\mathrm{T} 2 \mathrm{D}$ & GWAS & Diagnostic & {$[14]$} \\
\hline TPM1 & rs6494387 & African American & $\mathrm{T} 2 \mathrm{D}$ & GWAS & Diagnostic & {$[14]$} \\
\hline UNC5C & rs11730446 & African American & $\mathrm{T} 2 \mathrm{D}$ & GWAS & Diagnostic & {$[14]$} \\
\hline
\end{tabular}

of matrix metalloproteinases [103]. The same susceptibility locus was also identified in a T1DN Caucasian cohort [18]. Finally, recent data from a meta-analysis study suggests the ELMO1 association with DN exclusively in the T2D Asian subgroup [16].

In a population of Pima Indians with T2D, the GWAS of over 100,000 SNPs led to the identification of several loci with significant association for ESRD susceptibility, with the strongest signal located in the intronic region of the of PVT1 gene [22]. Some of these findings were also replicated in an ethnically different population with T1D [23].

In a GWAS performed on a large cohort of African Americans with T2D and ESRD, five gene regions with evidence of association with DN were detected, nominally, SASH1, RPS12, AUH, MSRB3-HMGA2, and LIMK2-SFI1. Some of these SNPs however were later found to contribute to all-cause ESRD [14].

In order to establish a comprehensive, well-defined DNA biobank for the genotyping of DN in T1D in particular, the Genetics of Kidneys in Diabetes (GoKinD) study was undertaken [104]. The first results of this genome-wide scan were reported by Pezzolesi et al. in 2009. Authors claimed that although no SNP achieved genome-wide significance, strong association was found near the 4.1 protein ezrin, radixin, and moesin [FERM] domain containing 3 (FRMD3) locus and near the cysteinyl-tRNA synthetase (CARS) locus [105]. Further studies confirmed the 9q21.32 region (upstream of FRMD3) as a susceptibility locus for T2DN in several unrelated study populations [20, 21].

Despite all the effort currently invested into this field of research, at present it is still impossible to predict those diabetic patients with a higher risk for developing DN. Indeed, in almost all the studies published so far on DN susceptibility, diagnosis was based almost exclusively on the presence of hyperglycemia and proteinuria; therefore, it is not possible to exclude that the inconsistencies among the findings could be linked to a misclassification of the renal damage in the diabetic population.

The genetic markers cited in this paper are also summarized in Table 1. 
TABLE 2: Gene expression markers. Collection of coding RNA transcripts showing deregulation in DN. List is ordered alphabetically. IHC: immunohistochemistry. SAGE: serial analysis of gene expression; NGS: next-generation sequencing.

\begin{tabular}{|c|c|c|c|c|c|c|c|}
\hline mRNA transcript & Sample type & $\begin{array}{c}\text { Tissue } \\
\text { compartment }\end{array}$ & Expression & $\begin{array}{l}\text { Diabetes } \\
\text { type }\end{array}$ & Assay type & $\begin{array}{l}\text { Potential value of } \\
\text { biomarker }\end{array}$ & References \\
\hline ABCA1 & Kidney & Whole & Down & $\mathrm{T} 2 \mathrm{D}$ & qPCR & Diagnostic/prognostic & {$[24]$} \\
\hline ABCG1 & Kidney & Whole & Down & $\mathrm{T} 2 \mathrm{D}$ & qPCR & Diagnostic/prognostic & {$[24]$} \\
\hline ACE & Kidney & Whole & Up & $\mathrm{T} 2 \mathrm{D}$ & qPCR & Diagnostic & {$[25]$} \\
\hline ACE & Kidney & Glomerular & Up & $\mathrm{T} 2 \mathrm{D}$ & qPCR & Diagnostic & {$[26]$} \\
\hline ACE & Urine & Sediment & $\mathrm{Up}$ & $\mathrm{T} 2 \mathrm{D}$ & qPCR & Diagnostic & {$[27]$} \\
\hline ACE2 & Kidney & Glomerular & Down & $\mathrm{T} 2 \mathrm{D}$ & qPCR & Diagnostic & {$[26]$} \\
\hline ACTN4 & Urine & Sediment & $\mathrm{Up}$ & $\mathrm{T} 2 \mathrm{D}$ & qPCR & Diagnostic & {$[28]$} \\
\hline ACTN4 & Urine & Sediment & Up & $\mathrm{T} 2 \mathrm{D}$ & qPCR & Diagnostic/prognostic & {$[29]$} \\
\hline ACTN4 & Urine & Sediment & Up & $\mathrm{T} 2 \mathrm{D}$ & qPCR & Diagnostic & {$[27]$} \\
\hline ANGPTL2 & Kidney & Glomerular & $\mathrm{Up}$ & $\mathrm{T} 2 \mathrm{D}$ & qPCR/IHC & Diagnostic & {$[30]$} \\
\hline ANKRD56 & Kidney & Whole & Down & $\mathrm{T} 2 \mathrm{D}$ & qPCR & Diagnostic & {$[31]$} \\
\hline apoE & Kidney & Whole & Down & $\mathrm{T} 2 \mathrm{D}$ & qPCR & Diagnostic/prognostic & {$[24]$} \\
\hline AQP1 & Kidney & Glomerular & Up & $\mathrm{T} 2 \mathrm{D}$ & Array & Diagnostic & {$[32]$} \\
\hline ATG5 & Kidney & Whole & Down & $\mathrm{T} 2 \mathrm{D}$ & $\mathrm{qPCR}$ & Diagnostic & [33] \\
\hline ATG7 & Kidney & Whole & Down & $\mathrm{T} 2 \mathrm{D}$ & qPCR & Diagnostic & {$[34]$} \\
\hline ATG8 & Kidney & Whole & Down & $\mathrm{T} 2 \mathrm{D}$ & qPCR & Diagnostic & {$[33]$} \\
\hline $\mathrm{B} 2 \mathrm{M}$ & Kidney & Tubulointerstitial & $\mathrm{Up}$ & $\mathrm{T} 1 \mathrm{D} / \mathrm{T} 2 \mathrm{D}$ & Array/qPCR & Diagnostic/prognostic & {$[35]$} \\
\hline B7-1 & Kidney & Whole & $\mathrm{Up}$ & $\mathrm{T} 2 \mathrm{D}$ & qPCR & Diagnostic & {$[36]$} \\
\hline BECN1 & Kidney & Whole & Down & $\mathrm{T} 2 \mathrm{D}$ & qPCR & Diagnostic & {$[33]$} \\
\hline BECN1 & Kidney & Whole & Down & $\mathrm{T} 2 \mathrm{D}$ & qPCR & Diagnostic & {$[34]$} \\
\hline BMP2 & Kidney & Glomerular & Down & $\mathrm{T} 2 \mathrm{D}$ & Array & Diagnostic & {$[32]$} \\
\hline $\mathrm{C} 3$ & Kidney & Glomerular & Up & $\mathrm{ND}$ & Array & Diagnostic & {$[37]$} \\
\hline CAPN3 & Kidney & Glomerular & Up & $\mathrm{T} 2 \mathrm{D}$ & Array & Diagnostic & {$[32]$} \\
\hline CCL2 & Kidney & Tubulointerstitial & Up & $\mathrm{T} 2 \mathrm{D}$ & qPCR/IHC & Diagnostic & {$[38]$} \\
\hline CCL5/RANTES & Kidney & Tubulointerstitial & Up & $\mathrm{T} 1 \mathrm{D} / \mathrm{T} 2 \mathrm{D}$ & $\mathrm{qPCR}$ & Diagnostic/prognostic & {$[35]$} \\
\hline CCR5 & Kidney & Tubulointerstitial & $\mathrm{Up}$ & $\mathrm{T} 2 \mathrm{D}$ & qPCR/IHC & Diagnostic & {$[38]$} \\
\hline CD2AP & Urine & Sediment & Up & $\mathrm{T} 2 \mathrm{D}$ & $\mathrm{qPCR}$ & Diagnostic/prognostic & \\
\hline CD36 & Kidney & Whole & Up & $\mathrm{T} 2 \mathrm{D}$ & qPCR & Diagnostic/prognostic & {$[24]$} \\
\hline CD68 & Kidney & Tubulointerstitial & Up & $\mathrm{T} 2 \mathrm{D}$ & qPCR/IHC & Diagnostic & {$[38]$} \\
\hline $\mathrm{CDH} 2$ & Urine & Sediment & $\mathrm{Up}$ & $\mathrm{T} 2 \mathrm{D}$ & $\mathrm{qPCR}$ & Diagnostic/prognostic & {$[27]$} \\
\hline CLIC5 & Kidney & Glomerular & Down & ND & Array/IHC & Diagnostic & {$[37]$} \\
\hline COL1A2 & Kidney & Tubulointerstitial & Up & $\mathrm{T} 1 \mathrm{D} / \mathrm{T} 2 \mathrm{D}$ & qPCR & Diagnostic & [39] \\
\hline COL1A2 & Kidney & Glomerular & Up & ND & Array & Diagnostic & {$[37]$} \\
\hline COL1A2 & Kidney & Tubular & Up & ND & Array & Diagnostic & {$[37]$} \\
\hline COL3A1 & Kidney & Tubular & Up & ND & Array & Diagnostic & {$[37]$} \\
\hline COL4A1 & Kidney & Tubulointerstitial & $\mathrm{Up}$ & $\mathrm{T} 1 \mathrm{D} / \mathrm{T} 2 \mathrm{D}$ & qPCR & Diagnostic & {$[39]$} \\
\hline COL4A1 & Urine & Sediment & Up & $\mathrm{T} 2 \mathrm{D}$ & qPCR & Diagnostic & {$[27]$} \\
\hline COL4A2 & Kidney & Tubulointerstitial & Up & $\mathrm{T} 1 \mathrm{D} / \mathrm{T} 2 \mathrm{D}$ & qPCR & Diagnostic & {$[39]$} \\
\hline COL6A3 & Kidney & Glomerular & $\mathrm{Up}$ & ND & Array & Diagnostic & {$[37]$} \\
\hline COL8A1 & Kidney & $\begin{array}{c}\text { Glomerular/ } \\
\text { tubulointerstitial }\end{array}$ & $\mathrm{Up}$ & $\mathrm{T} 2 \mathrm{D}$ & qPCR/IHC & Diagnostic & {$[40]$} \\
\hline COL8A2 & Kidney & $\begin{array}{c}\text { Glomerular/ } \\
\text { tubulointerstitial }\end{array}$ & Up & $\mathrm{T} 2 \mathrm{D}$ & qPCR/IHC & Diagnostic & {$[40]$} \\
\hline CTGF & Kidney & Glomerular & Down & $\mathrm{T} 2 \mathrm{D}$ & Array/qPCR/IHC & Diagnostic & {$[41]$} \\
\hline CXCL10/IP10 & Kidney & Tubulointerstitial & Up & $\mathrm{T} 1 \mathrm{D} / \mathrm{T} 2 \mathrm{D}$ & Array/qPCR & Diagnostic/prognostic & {$[35]$} \\
\hline CXCL16 & Kidney & Whole & Down & $\mathrm{T} 2 \mathrm{D}$ & $\mathrm{qPCR}$ & Diagnostic/prognostic & {$[24]$} \\
\hline
\end{tabular}


TABLe 2: Continued.

\begin{tabular}{|c|c|c|c|c|c|c|c|}
\hline mRNA transcript & Sample type & $\begin{array}{c}\text { Tissue } \\
\text { compartment }\end{array}$ & Expression & $\begin{array}{l}\text { Diabetes } \\
\text { type }\end{array}$ & Assay type & $\begin{array}{c}\text { Potential value of } \\
\text { biomarker }\end{array}$ & References \\
\hline CXCL6 & Kidney & Glomerular & Up & ND & Array & Diagnostic & [37] \\
\hline DKK3 & Kidney & Glomerular & Up & $\mathrm{T} 2 \mathrm{D}$ & Array & Diagnostic & {$[42]$} \\
\hline EDN1 & Kidney & Tubulointerstitial & Up & $\mathrm{T} 1 \mathrm{D} / \mathrm{T} 2 \mathrm{D}$ & qPCR & Diagnostic/prognostic & {$[35]$} \\
\hline EGF & Kidney & Tubulointerstitial & Down & $\mathrm{T} 1 \mathrm{D} / \mathrm{T} 2 \mathrm{D}$ & qPCR/IHC & Diagnostic/prognostic & [39] \\
\hline ENTPD8 & Kidney & Whole & Down & $\mathrm{T} 2 \mathrm{D}$ & qPCR & Diagnostic & {$[31]$} \\
\hline FAT1 & Urine & Sediment & Up & $\mathrm{T} 2 \mathrm{D}$ & qPCR & Diagnostic & {$[27]$} \\
\hline FGF-2 & Kidney & Tubulointerstitial & Up & $\mathrm{T} 2 \mathrm{D}$ & qPCR/IF & Diagnostic & [43] \\
\hline FN1 & Kidney & Tubulointerstitial & $\mathrm{Up}$ & $\mathrm{T} 1 \mathrm{D} / \mathrm{T} 2 \mathrm{D}$ & qPCR & Diagnostic & [39] \\
\hline FOXO1 & Kidney & Whole & Down & $\mathrm{T} 2 \mathrm{D}$ & qPCR/IHC & Diagnostic & {$[33]$} \\
\hline FOXO3A & Kidney & Whole & Down & $\mathrm{T} 2 \mathrm{D}$ & qPCR & Diagnostic & {$[33]$} \\
\hline FSP1 & Kidney & Glomerular & Up & $\mathrm{T} 2 \mathrm{D}$ & qPCR/ISH & Diagnostic/prognostic & {$[44]$} \\
\hline GREM1 & Kidney & Whole & Up & $\mathrm{T} 2 \mathrm{D}$ & qPCR/ISH/IHC & Diagnostic & {$[45]$} \\
\hline GREM1 & Kidney & Whole & Up & $\mathrm{T} 2 \mathrm{D}$ & qPCR/ISH & Diagnostic/prognostic & {$[46]$} \\
\hline HDAC2 & Kidney & Whole & Up & $\mathrm{T} 2 \mathrm{D}$ & qPCR/IHC & Diagnostic/prognostic & {$[34]$} \\
\hline HDAC4 & Kidney & Whole & Up & $\mathrm{T} 2 \mathrm{D}$ & qPCR/IHC & Diagnostic/prognostic & {$[34]$} \\
\hline HDAC5 & Kidney & Whole & Up & $\mathrm{T} 2 \mathrm{D}$ & qPCR/IHC & Diagnostic/prognostic & {$[34]$} \\
\hline HES1 & Kidney & Whole & Up & $\mathrm{T} 2 \mathrm{D}$ & qPCR/ISH & Diagnostic & {$[46]$} \\
\hline HLA-A & Kidney & Tubulointerstitial & Up & $\mathrm{T} 1 \mathrm{D} / \mathrm{T} 2 \mathrm{D}$ & Array/qPCR & Diagnostic/prognostic & [35] \\
\hline HLA-B & Kidney & Tubulointerstitial & Up & $\mathrm{T} 1 \mathrm{D} / \mathrm{T} 2 \mathrm{D}$ & Array/qPCR & Diagnostic/prognostic & {$[35]$} \\
\hline HSPA5 & Kidney & Tubulointerstitial & $\mathrm{Up}$ & $\mathrm{T} 2 \mathrm{D}$ & Array/qPCR & Diagnostic & {$[47]$} \\
\hline Hyaluronoglucosidase & Kidney & Glomerular & Up & $\mathrm{T} 2 \mathrm{D}$ & Array & Diagnostic & {$[32]$} \\
\hline HYOU1 & Kidney & Tubulointerstitial & Up & $\mathrm{T} 2 \mathrm{D}$ & Array/qPCR & Diagnostic & {$[47]$} \\
\hline IFNB1 & Kidney & Tubulointerstitial & Up & $\mathrm{T} 1 \mathrm{D} / \mathrm{T} 2 \mathrm{D}$ & $\mathrm{qPCR}$ & Diagnostic/prognostic & {$[35]$} \\
\hline IGF-1 & Kidney & Glomerular & Down & $\mathrm{T} 2 \mathrm{D}$ & Array & Diagnostic & {$[32]$} \\
\hline IGFBP-2 & Kidney & Glomerular & Down & $\mathrm{T} 2 \mathrm{D}$ & Array & Diagnostic & {$[32]$} \\
\hline IGH & Kidney & Glomerular & Up & ND & Array & Diagnostic & {$[37]$} \\
\hline IGH & Kidney & Tubular & Up & ND & Array & Diagnostic & {$[37]$} \\
\hline IGL & Kidney & Tubular & Up & ND & Array & Diagnostic & {$[37]$} \\
\hline IHG-1 & Kidney & Tubulointerstitial & Up & $\mathrm{T} 2 \mathrm{D}$ & ISH & Diagnostic & {$[48]$} \\
\hline IL6 & Kidney & Tubulointerstitial & Up & $\mathrm{T} 2 \mathrm{D}$ & qPCR/IHC & Diagnostic & {$[38]$} \\
\hline IRS2 & Kidney & Tubulointerstitial & Up & $\mathrm{T} 2 \mathrm{D}$ & ISH & Diagnostic & {$[49]$} \\
\hline JAG1 & Kidney & Whole & Up & $\mathrm{T} 2 \mathrm{D}$ & qPCR/ISH & Diagnostic & {$[46]$} \\
\hline JAK2 & Kidney & $\begin{array}{c}\text { Glomerular/ } \\
\text { tubulointerstitial }\end{array}$ & Up & $\mathrm{T} 2 \mathrm{D}$ & Array/qPCR/IHC & Diagnostic/prognostic & {$[50]$} \\
\hline LC3 & Kidney & Whole & Down & $\mathrm{T} 2 \mathrm{D}$ & qPCR & Diagnostic & [33] \\
\hline LC3 & Kidney & Whole & Down & $\mathrm{T} 2 \mathrm{D}$ & qPCR & Diagnostic & {$[34]$} \\
\hline LDLR & Kidney & Whole & Up & $\mathrm{T} 2 \mathrm{D}$ & qPCR & Diagnostic/prognostic & {$[24]$} \\
\hline LEF1 & Kidney & Glomerular & Up & $\mathrm{T} 2 \mathrm{D}$ & Array & Diagnostic & {$[42]$} \\
\hline LOX1 & Kidney & Whole & Up & $\mathrm{T} 2 \mathrm{D}$ & $\mathrm{qPCR}$ & Diagnostic/prognostic & {$[24]$} \\
\hline MMP14 & Kidney & Tubulointerstitial & Up & $\mathrm{T} 1 \mathrm{D} / \mathrm{T} 2 \mathrm{D}$ & qPCR & Diagnostic & {$[39]$} \\
\hline MMP2 & Kidney & Tubulointerstitial & Up & $\mathrm{T} 1 \mathrm{D} / \mathrm{T} 2 \mathrm{D}$ & qPCR & Diagnostic & {$[39]$} \\
\hline MMP7 & Kidney & Tubulointerstitial & Up & ND & Array/qPCR/IHC & Diagnostic & {$[51]$} \\
\hline MMP7 & Kidney & Tubulointerstitial & Up & $\mathrm{T} 1 \mathrm{D} / \mathrm{T} 2 \mathrm{D}$ & qPCR & Diagnostic & {$[39]$} \\
\hline MRP8 & Kidney & Glomerular & Up & $\mathrm{T} 2 \mathrm{D}$ & qPCR/IHC & Diagnostic/prognostic & {$[52]$} \\
\hline NOTCH3 & Urine & Sediment & Up & $\mathrm{T} 2 \mathrm{D}$ & $\mathrm{qPCR}$ & Diagnostic & {$[27]$} \\
\hline NPHS1 & Kidney & Glomerular & Down & $\mathrm{T} 2 \mathrm{D}$ & Array & Diagnostic & {$[41]$} \\
\hline NPHS1 & Kidney & Glomerular & Down & $\mathrm{T} 2 \mathrm{D}$ & Array/IHC & Diagnostic & {$[32]$} \\
\hline NPHS1 & Urine & Sediment & Up & $\mathrm{T} 2 \mathrm{D}$ & qPCR & Diagnostic & {$[53]$} \\
\hline
\end{tabular}


TABLe 2: Continued.

\begin{tabular}{|c|c|c|c|c|c|c|c|}
\hline mRNA transcript & Sample type & $\begin{array}{c}\text { Tissue } \\
\text { compartment }\end{array}$ & Expression & $\begin{array}{l}\text { Diabetes } \\
\text { type }\end{array}$ & Assay type & $\begin{array}{l}\text { Potential value of } \\
\text { biomarker }\end{array}$ & References \\
\hline NPHS1 & Kidney & Whole & Down & $\mathrm{T} 2 \mathrm{D}$ & ISH & Diagnostic/prognostic & {$[54]$} \\
\hline NPHS1 & Urine & Sediment & Up & $\mathrm{T} 2 \mathrm{D}$ & qPCR & Diagnostic/prognostic & {$[28]$} \\
\hline NPHS1 & Kidney & Glomerular & Down & ND & Array & Diagnostic & [37] \\
\hline NPHS2 & Kidney & Glomerular & Down & $\mathrm{T} 2 \mathrm{D}$ & Array & Diagnostic & {$[41]$} \\
\hline NPHS2 & Urine & Sediment & Up & $\mathrm{T} 2 \mathrm{D}$ & qPCR & Diagnostic & {$[53]$} \\
\hline NPHS2 & Urine & Sediment & Up & $\mathrm{T} 2 \mathrm{D}$ & qPCR & Diagnostic/prognostic & {$[28]$} \\
\hline NPHS2 & Kidney & Glomerular & Down & ND & Array/IHC & Diagnostic/prognostic & {$[37]$} \\
\hline NPHS2 & Urine & Sediment & Up & $\mathrm{T} 2 \mathrm{D}$ & qPCR & Diagnostic & [29] \\
\hline NRP1 & Kidney & Glomerular & Down & $\mathrm{T} 2 \mathrm{D}$ & qPCR & Diagnostic & {$[55]$} \\
\hline NRP2 & Kidney & Glomerular & Down & $\mathrm{T} 2 \mathrm{D}$ & $\mathrm{qPCR}$ & Diagnostic & {$[55]$} \\
\hline OPG & Kidney & Tubulointerstitial & Up & $\mathrm{T} 2 \mathrm{D}$ & Array/qPCR & Diagnostic/prognostic & {$[56]$} \\
\hline PDGF-A & Kidney & Whole & Up & $\mathrm{T} 2 \mathrm{D}$ & qPCR/IHC & Diagnostic & {$[57]$} \\
\hline PDGF-B & Kidney & Whole & Up & $\mathrm{T} 2 \mathrm{D}$ & qPCR/IHC & Diagnostic & {$[57]$} \\
\hline PECAM-1 & Kidney & Glomerular & Up & $\mathrm{T} 2 \mathrm{D}$ & Array & Diagnostic & {$[32]$} \\
\hline $\operatorname{PKC} \alpha$ & Kidney & Glomerular & Up & $\mathrm{T} 2 \mathrm{D}$ & qPCR/IHC & Diagnostic & {$[58]$} \\
\hline PLA2R1 & Kidney & Glomerular & Down & ND & Array & Diagnostic & [37] \\
\hline PLCE1 & Kidney & Glomerular & Down & ND & Array & Diagnostic & {$[37]$} \\
\hline PODXL & Kidney & Glomerular & Down & ND & Array & Diagnostic & {$[37]$} \\
\hline PODXL & Urine & Sediment & Up & $\mathrm{T} 2 \mathrm{D}$ & qPCR & Diagnostic/prognostic & [29] \\
\hline PRKCB & Kidney & Whole & Up & $\mathrm{T} 2 \mathrm{D}$ & qPCR & Diagnostic & [59] \\
\hline PTGDS & Kidney & Glomerular & Down & ND & Array & Diagnostic & {$[37]$} \\
\hline $\mathrm{ROBO} 2$ & Kidney & Glomerular & Down & $\mathrm{T} 2 \mathrm{D}$ & qPCR & Diagnostic & {$[60]$} \\
\hline SMPDL3b & Kidney & Glomerular & Up & $\mathrm{T} 2 \mathrm{D}$ & Array & Diagnostic & {$[61]$} \\
\hline STAT1 & Kidney & Whole & Up & $\mathrm{T} 2 \mathrm{D}$ & qPCR/IHC & Diagnostic & {$[33]$} \\
\hline SYNPO & Urine & Sediment & $\mathrm{Up}$ & $\mathrm{T} 2 \mathrm{D}$ & qPCR & Diagnostic & {$[28]$} \\
\hline SYNPO & Kidney & Glomerular & Down & ND & Array & Diagnostic & {$[37]$} \\
\hline SYNPO & Urine & Sediment & Up & $\mathrm{T} 2 \mathrm{D}$ & qPCR & Diagnostic/prognostic & [29] \\
\hline SYNPO & Urine & Sediment & Up & $\mathrm{T} 2 \mathrm{D}$ & qPCR & Diagnostic & {$[27]$} \\
\hline TIMP1 & Kidney & Tubulointerstitial & Up & $\mathrm{T} 1 \mathrm{D} / \mathrm{T} 2 \mathrm{D}$ & qPCR & Diagnostic & [39] \\
\hline TIMP1 & Urine & Sediment & Down & $\mathrm{T} 2 \mathrm{D}$ & $\mathrm{qPCR}$ & Diagnostic & [27] \\
\hline TIMP3 & Kidney & Whole & Down & $\mathrm{T} 2 \mathrm{D}$ & qPCR/IHC & Diagnostic & {$[33]$} \\
\hline TIMP3 & Kidney & Tubulointerstitial & Up & $\mathrm{T} 1 \mathrm{D} / \mathrm{T} 2 \mathrm{D}$ & qPCR & Diagnostic & [39] \\
\hline TIPE2 & Kidney & Whole & Up & $\mathrm{T} 2 \mathrm{D}$ & qPCR/WB & Diagnostic & {$[62]$} \\
\hline TLR4 & Kidney & $\begin{array}{c}\text { Glomerular/ } \\
\text { tubulointerstitial }\end{array}$ & Up & $\mathrm{T} 2 \mathrm{D}$ & qPCR/IHC & Diagnostic/prognostic & {$[38]$} \\
\hline TNFAIP8 & Kidney & Whole & Up & $\mathrm{T} 2 \mathrm{D}$ & $\mathrm{qPCR} / \mathrm{WB}$ & Diagnostic & {$[62]$} \\
\hline TRAIL & Kidney & Tubulointerstitial & Up & $\mathrm{T} 2 \mathrm{D}$ & Array/IHC/qPCR & Diagnostic/prognostic & {$[56]$} \\
\hline TWIST1 & Urine & Sediment & Up & $\mathrm{T} 2 \mathrm{D}$ & $\mathrm{qPCR}$ & Diagnostic & {$[27]$} \\
\hline UII & Kidney & Whole & Up & $\mathrm{T} 2 \mathrm{D}$ & qPCR/IHC & Diagnostic & {$[63]$} \\
\hline UT & Kidney & Whole & Up & $\mathrm{T} 2 \mathrm{D}$ & qPCR & Diagnostic & {$[63]$} \\
\hline VCAM1 & Kidney & Tubulointerstitial & Up & $\mathrm{T} 1 \mathrm{D} / \mathrm{T} 2 \mathrm{D}$ & Array/qPCR & Diagnostic/prognostic & [35] \\
\hline VEGF & Kidney & Glomerular & Down & $\mathrm{T} 2 \mathrm{D}$ & Array/qPCR/IHC & Diagnostic & [41] \\
\hline VEGF & Kidney & Glomerular & Down & $\mathrm{T} 2 \mathrm{D}$ & Array/IHC & Diagnostic/prognostic & {$[32]$} \\
\hline VEGF & Kidney & Glomerular & Down & $\mathrm{T} 2 \mathrm{D}$ & qPCR & Diagnostic/prognostic & {$[64]$} \\
\hline VEGF & Kidney & Whole & Up & $\mathrm{T} 2 \mathrm{D}$ & ISH/IHC & Diagnostic & {$[65]$} \\
\hline VEGF & Kidney & Tubulointerstitial & Down & $\mathrm{T} 1 \mathrm{D} / \mathrm{T} 2 \mathrm{D}$ & qPCR/IHC & Diagnostic/prognostic & {$[39]$} \\
\hline WNT1 & Kidney & Glomerular & $\mathrm{Up}$ & $\mathrm{T} 2 \mathrm{D}$ & Array & Diagnostic & {$[42]$} \\
\hline WNT16 & Kidney & Glomerular & Up & $\mathrm{T} 2 \mathrm{D}$ & Array & Diagnostic & {$[42]$} \\
\hline
\end{tabular}


TABLE 2: Continued.

\begin{tabular}{|c|c|c|c|c|c|c|c|}
\hline mRNA transcript & Sample type & $\begin{array}{c}\text { Tissue } \\
\text { compartment }\end{array}$ & Expression & $\begin{array}{l}\text { Diabetes } \\
\text { type }\end{array}$ & Assay type & $\begin{array}{c}\text { Potential value of } \\
\text { biomarker }\end{array}$ & References \\
\hline WNT2B & Kidney & Glomerular & Up & $\mathrm{T} 2 \mathrm{D}$ & Array & Diagnostic & {$[42]$} \\
\hline WNT4 & Kidney & Glomerular & Up & $\mathrm{T} 2 \mathrm{D}$ & Array & Diagnostic & {$[42]$} \\
\hline WNT6 & Kidney & Glomerular & Up & $\mathrm{T} 2 \mathrm{D}$ & Array & Diagnostic & {$[42]$} \\
\hline WT1 & Kidney & Glomerular & Down & $\mathrm{T} 2 \mathrm{D}$ & Array/IHC & Diagnostic & {$[41]$} \\
\hline WT1 & Urine & Sediment & Up & $\mathrm{T} 2 \mathrm{D}$ & qPCR & Diagnostic & {$[28]$} \\
\hline WT1 & Kidney & Glomerular & Down & ND & Array & Diagnostic/prognostic & [37] \\
\hline XBP1 & Kidney & Tubulointerstitial & Up & $\mathrm{T} 2 \mathrm{D}$ & Array/qPCR & Diagnostic & [47] \\
\hline
\end{tabular}

TABLE 3: Noncoding RNA markers. Collection of noncoding RNA transcripts deregulated in DN samples. List is ordered alphabetically.

\begin{tabular}{|c|c|c|c|c|c|c|}
\hline miRNA transcript & Sample type & Expression & Assay type & Diabetes type & Potential value of biomarker & References \\
\hline hsa-miR-1205 & Mesangial cells & $\mathrm{Up}$ & $\mathrm{qPCR}$ & - & Descriptive & {$[66]$} \\
\hline hsa-miR-129 & Human mesangial cells & Up & Array/qPCR & - & - & {$[67]$} \\
\hline hsa-miR-130a & Urinary exosomes & Up & qPCR & T1D & Diagnostic & {$[68]$} \\
\hline hsa-miR-145 & Urinary exosomes & $\mathrm{Up}$ & qPCR & T1D & Diagnostic & {$[68]$} \\
\hline hsa-miR-146a & Kidney & Up & Array/qPCR & $\mathrm{T} 2 \mathrm{D}$ & Diagnostic & {$[69]$} \\
\hline hsa-miR-15 & Urinary sediment & Down & qPCR & - & Diagnostic/prognostic & {$[70]$} \\
\hline hsa-miR-155 & Urinary exosomes & Down & qPCR & T1D & Diagnostic/prognostic & {$[68]$} \\
\hline hsa-miR-155 & Kidney & Up & Array/qPCR & $\mathrm{T} 2 \mathrm{D}$ & Prognostic & {$[69]$} \\
\hline hsa-miR-188-3p & Urine & Down & qPCR & T1D & Prognostic & {$[71]$} \\
\hline hsa-miR-1913 & Urine & Up & $\mathrm{qPCR}$ & T1D & Prognostic & {$[71]$} \\
\hline hsa-miR-192 & Kidney & Down & qPCR/ISH & - & Diagnostic/prognostic & [72] \\
\hline hsa-miR-192 & Human mesangial cells & Up & Array & - & - & {$[67]$} \\
\hline hsa-miR-192 & Urinary sediment & Down & qPCR & - & Diagnostic/prognostic & {$[73]$} \\
\hline hsa-miR-21 & Kidney & Up & $\mathrm{qPCR}$ & $\mathrm{T} 2 \mathrm{D}$ & Diagnostic & {$[74]$} \\
\hline hsa-miR-214-3p & Urine & Up & qPCR & T1D & Prognostic & {$[71]$} \\
\hline hsa-miR-221-3p & Urine & Down & qPCR & T1D & Prognostic & {$[71]$} \\
\hline hsa-miR-29a & Urine & $\mathrm{Up}$ & qPCR & $\mathrm{T} 2 \mathrm{D}$ & Prognostic & {$[75]$} \\
\hline hsa-miR-323b-5p & Urine & Down & qPCR & T1D & Prognostic & {$[71]$} \\
\hline hsa-miR-337 & Human mesangial cells & Up & Array/qPCR & - & - & {$[67]$} \\
\hline hsa-miR-373-5p & Urine & $\mathrm{Up}$ & qPCR & T1D & Prognostic & {$[71]$} \\
\hline hsa-miR-377 & Human mesangial cells & $\mathrm{Up}$ & Array/qPCR & - & - & {$[67]$} \\
\hline hsa-miR-424 & Urinary exosomes & Down & qPCR & T1D & Prognostic & {$[68]$} \\
\hline hsa-miR-429 & Urine & Up & qPCR & T1D & Prognostic & {$[71]$} \\
\hline hsa-miR-524-5p & Urine & Down & qPCR & $\mathrm{T} 1 \mathrm{D}$ & Prognostic & {$[71]$} \\
\hline hsa-miR-638 & Urine & Up & qPCR & T1D & Prognostic & {$[71]$} \\
\hline hsa-miR-765 & Urine & Up & qPCR & T1D & Prognostic & {$[71]$} \\
\hline hsa-miR-92b-5p & Urine & Up & qPCR & T1D & Prognostic & {$[71]$} \\
\hline let-7a & Whole blood & Down & Array/qPCR & $\mathrm{T} 2 \mathrm{D}$ & Diagnostic & {$[76]$} \\
\hline PVT1 (lncRNA) & Mesangial cells & Up & $\mathrm{qPCR}$ & - & Descriptive & {$[66]$} \\
\hline
\end{tabular}

\section{Transcriptome Profiling of DN}

The transcriptome represents the part of genome that is transcribed and includes both coding and noncoding RNA molecules. When studying the transcriptome, as for genetic studies, either targeted or genome-wide approaches can be used. RNA-sequencing (RNA-seq), arrays, and quantitative PCR (qPCR) are the techniques employed routinely to assess
RNA expression. qPCR is very sensitive and even subtle changes can be detected precisely; arrays on the other hand are very high-throughput but also less sensitive. RNA-seq takes advantage of the recent next-generation sequencing platforms and it has rapidly become the method of choice for transcriptome profiling. The main advantages of RNASeq are its very high resolution (down to a single nucleotide), its potential to detect novel transcripts, its ability to measure 
either primary transcripts or spliced mature mRNAs. Given the plethora of gene expression data available in the literature, only the research on DN kidney tissue or urine will be discussed. All the coding and noncoding RNA markers cited in this paper are also summarized in Tables 2 and 3, respectively.

3.1. Coding RNA Studies. The first transcriptomic signature of DN kidney was published in 2004. Using an arraybased approach, Baelde et al. assayed the glomerular gene expression profile of T2DN and morphologically normal, nondiabetic kidneys. The results of this genome-wide analysis indicated that 96 genes were upregulated in T2DN, including aquaporin 1 (AQP1), calpain 3 (CAPN3), hyaluronoglucosidase, and platelet/endothelial cell adhesion molecule (PECAM-1). Over 500 genes were downregulated, including bone morphogenetic protein 2 (BMP2), vascular endothelial growth factor (VEGF), fibroblast growth factor 1 (IGF-1), insulin-like growth factor binding protein 2 (IGFBP-2), and nephrin. In the same manuscript, authors confirmed reduced expression of VEGF and nephrin in renal biopsy specimens from additional DN patients at both the protein and RNA levels [32].

To explain the existing inconsistencies between human and murine progressive DN, microdissected biopsies from controls, early and progressive T2DN patients underwent global gene expression profiling through microarray hybridization. Preliminary results, later confirmed using qPCR, revealed an upregulation of Jak-2 and a compromised expression of several members within the Jak/Stat signaling pathway which could not be detected in either $d b / d b$ C57BLKS or diabetic STZ-treated DBA/2J mice [50].

More recently, Woroniecka et al. performed the transcriptome analysis on microdissected kidney biopsies from DN patients, healthy living transplant donors, and patients undergoing tumor nephrectomies (analyzing the histologically normal kidney tissue). The microarray-derived expression profiles indicated that several podocyte-specific transcripts were downregulated, including PLCE1, PTGDS, NPHS1, NPHS2, SYNPO, PLA2R1, WT1, CLIC5, and PODXL. Glomerular transcripts showing upregulation included IGH, C3, COL1A2, CXCL6, and COL6A3. In the tubular compartment instead, authors detected increased expression of different transcripts including IGH, IGL, COL1A2, and COL3A1 [37].

Several reports analyzed the gene expression of both the glomerular and tubular compartments of T2DN kidney biopsies. Among the mRNA transcripts detected as enriched in the glomerular compartment of T2DN individuals are MRP8 [52], WNT1, WNT2B, WNT4, WNT6, WNT16, DKK3, and Lef1 [42], PKC $\alpha$ [58], FSP1 [44], ANGPTL2 [30], and ACE [26]. Decreased expression for ACE2 [26], VEGF [64, 106], CTGF, nephrin, podocin, and WT1 [41] was also reported in T2DN glomeruli.

When assaying microdissected, tubule-rich renal biopsies from patients with T2DN, IHG-1 [48], IL6, CCL2 CD68, and CCR5 [38] were increased, while TLR4 was overexpressed in both glomeruli and tubules of microalbuminuric and overt DN [38].

Using biopsy material collected by the European Renal cDNA Bank, the gene expression of tubulointerstitial mRNA from human DN kidneys was compared to that of living donors, cadaveric donors, and patients with minimal change disease through a combined microarray profiling and qPCR validation approach. Results indicated dysregulation of specific NF- $\kappa \mathrm{B}$ targets, highlighting the existence of an inflammatory signature characteristic of progressive $\mathrm{DN}$. Eight genes in particular were induced in T1DN and T2DN relative to controls: CCL5/RANTES, CXCL10/IP10, EDN1, VCAM1, HLA-A, HLA-B, IFNB1, and B2M [35].

Further work performed using the European Renal cDNA Bank material highlighted additional mRNA transcripts as dysregulated in T2DN kidney when compared to normal tissue. Within the glomerular compartment in particular, NRP1 and NRP2 were significantly lower in T2DN [55], while SMPDL3b was increased [61]. Within the tubulointerstitial compartment, upregulation of MMP7 [51] and FGF-2 [43], of the unfolded protein response genes HSPA5, HYOU1, and XBP1 [47] and of the apoptosis-related genes TRAIL and OPG [56], were observed.

In other cases, the expression of several transcripts was assessed on whole T2DN kidney tissue.

Upregulated mRNAs included HDAC2, HDAC4, and HDAC5 [34], B7-1 [36], Stat1 [33], TNFAIP8 and TIPE2 [62], PRKC-beta [59], VEGF [65], UII and UT [63], PDGF-A and PDGF-B [57], LOX1, LDLR, and CD36 [24], Jagged1/Hes1 [46], and Gremlin [45, 46].

Decreased transcription was detected for autophagyrelated genes Beclin 1, LC3 [33, 34] and ATG7 [34], CXCL16, ABCA1, ABCG1, and apoE [24], Timp3, FoxO1 and FoxO3A, Atg5, and Atg8 [33], ANKRD56 and ENTPD8 [31], and nephrin [54].

In other works the study design was developed to compare T2DN with other glomerulopathies. Using a qPCR based approach, the tubulointerstitial compartment isolated from kidney biopsies of both DN patients, living donors, and minimal change disease patients was profiled specifically for the expression of 202 candidate genes involved in molecular pathways contributing to DN progression. Results showed a decreased expression of VEGF and EGF, while Collagens I and IV, fibronectin 1 , and vimentin as well as matrix metalloproteinases 2, 7, and 14 and tissue inhibitor of metalloproteinases 1 and 3 were increased [39]. In another study, increased IRS2 mRNA was detected in DN patients compared to controls, while no significant changes IRS2 expression were present in biopsies from patients with focalsegmental glomerulosclerosis or membranous nephropathy [49].

Low expression of $\mathrm{ROBO} 2$ mRNA was present in DN compared to nephrosclerosis, focal-segmental glomerulosclerosis, membranous nephropathy, and control pretransplant biopsies [60].

A strong specific induction of COL8A1 and COL8A2 mRNAs expression was found in both glomerular and tubular compartments of biopsies from patients with T2DN versus control pretransplant biopsies, benign nephrosclerosis, and focal-segmental glomerulosclerosis [40]. Finally, increased ACE expression was observed in T2DN biopsies compared to benign nephrosclerosis, minimal change nephrotic syndrome, and lupus nephritis [25]. 
Aiming to develop a diagnostic tool for early DN diagnosis, Zheng et al. designed a PCR-array platform to detect expression changes in 88 genes simultaneously and employed it in a pilot study where the urinary sediment of DN patients was assayed. Authors found that several mRNAs were significantly increased in $\mathrm{DN}$ compared to healthy controls, in particular, NOTCH3, ACTN4, CDH2, ACE, FAT1, COL4A1, SYNPO, and TWIST1 [27]. Similar studies investigated the mRNA derived from the urinary sediment of T2DN patients. Increased mRNA levels of podocalyxin, CD2-AP [29], nephrin, WT-1 [28], $\alpha$-actinin 4 podocin, and synaptopodin $[28,29]$ were found in the DN group compared with controls. Finally, in another work, authors claim that urinary expression of nephrin and podocin was useful for distinguishing diagnostic groups (IgA nephropathy, minimal change disease, and membranous nephropathy) as well as predicting renal function decline [53].

3.2. Noncoding RNA Studies. Until a few years ago, the molecular profiling of DN was mainly focused on the characterization of mRNA transcripts. Over the last decade however, much interest has converged toward the profiling of noncoding RNA (ncRNA) molecules. The ability of ncRNAs to modulate gene expression along with the discovery that they can be detected in biofluids and are fairly stable makes them ideal biomarker candidates.

microRNAs (miRNAs) are probably the most studied ncRNAs; they are short, single-stranded, highly conserved, and tissue-specific. miRNAs regulate protein synthesis through perfect partial match binding to their precursor messenger RNA. The partial match binding feature allows miRNAs to bind hundreds of targets simultaneously; accordingly the dysregulation of even one single miRNA molecule can profoundly influence the gene expression profile of the surrounding environment. For a complete review on miRNAs biogenesis and function refer to $[107,108]$. In the field of DN, the majority of miRNA's profiling studies was performed on cellular and animal models. More recently, with the surprising discovery that miRNAs can be released and carried into the extracellular environment, different body fluids are being characterized in their miRNA's content.

The first miRNA to be recognized as relevant contributor to DN progression was miR-192 [109]. Initially identified in a mice model of DN, miR-192, along with miR-377, miR337, and miR-129, was later discovered as being enriched in human mesangial cells (MCs) exposed to high glucose [67]. Interestingly, when assessing miR-192 in human DN kidney, expression levels not only are reduced but also inversely correlate with severity of kidney disease [72], raising once again the issue about the appropriateness of the currently available animal models for DN.

miR-21 has recently emerged as a marker for fibrosis in many complications [110, 111]; unsurprisingly, increased miR-21 expression was also detected in human T2DN kidney biopsies relative to healthy controls [74].

Except for the previously mentioned DN kidney profiling from Krupa et al., the array-based miRNome analysis of T2DN kidneys was recently published by Huang et al. and uncovered miR-155 and miR-146a enrichment in these samples [69]. These two are the only works describing the miRNome of human DN kidney; noteworthy, the existence of strict renal biopsy policies in most nephrology clinics might be a limiting factor in terms of sample collection and availability. In parallel, the urgent need for novel biomarkers of diagnosis and progression shifted priority to the profiling of more accessible samples, such as biological fluids.

Using a qPCR based approach, Argyropoulos et al. were the first to perform the urinary miRNA profiling of T1D patients with and without proteinuria. Results showed that miR-323b-5p, miR-221-3p, miR-524-5p, and miR-188-3p were underexpressed in albuminuric relative to nonalbuminuric patients, while miR-214-3p, miR-92b-5p, hsa-miR-765, hsamiR-429, miR-373-5p, miR-1913, and miR-638 were overexpressed [71]. In a similar study performed on the RNA content of urinary exosomes, authors showed that miR-130a and miR-145 were enriched in T1D patients with microalbuminuria compared to normoalbuminuric subjects, while miR-155 and miR-424 were reduced [68].

In a work aimed to determine the urinary levels of all miR-29 family members (miR-29a, miR-29b, and miR-29c), miR-29a was significantly increased in albuminuric T2DN patients compared to normoalbuminuric patients and it also correlated with the degree of albuminuria [75].

In the work from Szeto et al., when comparing the urinary sediment of patients with either IgA nephropathy, DN, or hypertensive nephrosclerosis, miR-15 was decreased in DN samples compared to other groups [70]. Similarly, in another work authors found that miR-192 levels were reduced in urinary sediment of DN patients compared to both healthy controls and patients with either minimal change nephropathy, focal glomerulosclerosis, membranous nephropathy, or other diagnosis groups [73].

miRNAs expression was also measured in venous blood from T2D Han Chinese patients with and without albuminuria. Using a microarray-based approach, authors identified several differentially expressed miRNAs in the different study population and confirmed miRNA let-7a downregulation using qPCR. Very interestingly, authors also observed how the distribution of a specific variant within let-7a (rs1143770) was significantly higher in diabetic patients (with and without albuminuria) relative to control subjects [76].

Finally, dysregulation of a new class of noncoding RNA molecules has emerged as being potentially involved in different complications, including kidney disease. Among these noncoding RNA molecules, recent effort aims to characterize the so-called long noncoding RNAs (lncRNAs). Compared to miRNAs lncRNAs are longer than 200 nucleotides and are poorly conserved. This led to the initial assumption that lncRNAs were not biologically relevant. Today we know that lncRNAs contain individual domains and structural motifs that allow them to specifically associate with DNA, RNA, and/or protein and thus regulate their function.

The first lncRNA identified in kidney disease was PVT1. As previously discussed, multiple experimental evidence, from different ethnic populations, suggested a link between diabetic kidney disease and genetic variants within the PVT1 locus $[22,23]$. PVT1, whose increase is significant in 
TABLE 4: Epigenetic markers. List of epigenetic marks identified in DN. List is ordered alphabetically.

\begin{tabular}{|c|c|c|c|c|c|}
\hline Locus & Sample type & Type of modification & Diabetes type & Potential value of biomarker & References \\
\hline $\mathrm{SHC1}$ & PBMC & Reduced promoter methylation & - & Diagnostic & [77] \\
\hline UNC13B & Whole blood & Increased DNA methylation & T1D & Diagnostic/prognostic & [78] \\
\hline
\end{tabular}

mesangial cells stimulated with high glucose, can induce the expression of plasminogen activator inhibitor 1 (PAI-1) and transforming growth factor beta 1 (TGF- $\beta 1$ ) [112]. Noteworthy, six different miRNAs are encoded within the PVT1 gene; therefore, authors investigated whether an alteration in PAI1 and TGF- $\beta 1$ gene expression was ascribable to the PVT1 lncRNA transcript itself or whether it was the result of a mutation within the miRNAs encoded in the PVT1 gene. Results showed that both PVT1 lncRNA and miR-1207-5p were induced by high glucose independently and they both contributed to ECM accumulation in the kidney [66].

\section{Epigenetic Studies in DN}

The term epigenetics refers to all those dynamic structural changes that, while not resulting from an alteration in the DNA sequence, affect gene expression and can be inherited. Epigenetic modifications, such as DNA methylation, histone methylation, and histone acetylation, modify the accessibility of the chromatin and thus modulate transcription. They are responsible for the phenotypic differences within cell types and explain why the gene expression profile of an organism can change so profoundly during development. Unlike genetics, epigenetics is highly susceptible to influences from the environment; therefore, the understanding of its regulatory machinery offers an incredible opportunity for disease management.

The study of epigenetics in diabetic kidney disease is still in its embryonic phase although increasing evidence indicates metabolic memory as a consequence of long-lasting epigenetic modifications contributing to $\mathrm{DN}$ progression [113]. In 2007 Geisel et al. analyzed the promoter methylation of the stress response protein p66Shc, previously shown to increase susceptibility to oxidative stress and atherosclerosis [114]. In peripheral blood mononuclear cells isolated from ESRD patients and control subjects, authors demonstrated that increased p66Shc expression in ESRD group was linked to a significant reduction in the methylation of its promoter region [77].

Using an array based approach, the genome-wide promoter DNA methylation of 192 T1D patients was analyzed searching for any possible association with $\mathrm{DN}$. The analysis was conducted using DNA extracted from peripheral blood cells as these include the $\mathrm{T}$ cell population responsible for islet beta cells destruction in T1D. Importantly, among the several CpG islands showing correlation with DN development, results uncovered one in particular (rs10081672), located upstream of the UNC13B gene. Additionally, this region is in strong linkage disequilibrium with rs13293564, a variant associated with DN susceptibility. Importantly, depending on which allele is present in rs10081672, a CpG site is either created or abrogated, thereby affecting transcription factor binding [78].

In another work, the genome-wide DNA methylation of diabetic patients with ESRD and diabetic patients without nephropathy was compared with the aim to identify novel disease biomarkers for noninvasive diagnosis. Patients' saliva was employed as starting material for DNA extraction while the study population included African Americans and Hispanic individuals. Results highlighted differential methylation at two or more CpG sites in 187 genes between the two groups. Interestingly, many of these genes are involved in inflammation, oxidative stress, ubiquitination, fibrosis, and drug metabolism, and some in particular are even known for their genetic association with $\mathrm{DN}$, suggesting once again a very close connection between genetic dysregulation and epigenetic dysregulation in the pathogenesis of DN [115].

A recent paper from Hasegawa et al. demonstrated that Sirtl, a protein deacetylase that targets histones and transcription factors, is reduced in STZ-treated mice. Using a transgenic mouse model authors also elucidated the interaction between Sirtl expression and CpG methylation of Cldn1, a gene encoding for the protein Claudin-1. Claudin-1 is a tight junction protein involved in cell-to-cell adhesion and authors suggest that its epigenetic-mediated induction is responsible for podocyte effacement and proteinuria. In support of this hypothesis authors also revealed the correlation between proteinuria and Sirtl expression in human DN kidney [116].

Finally, Reddy et al. elegantly demonstrated the link between the protective effect of angiotensin II receptor antagonist, losartan, and its ability to reverse specific epigenetic modifications in the glomeruli of diabetic $d b / d b$ mice [117]. The epigenetic marks cited in this paper are listed in Table 4.

All these experimental evidences show that epigenetics holds the potential to allow a temporary and reversible manipulation of the gene expression, conferring protection from disease progression. They also highlight the importance of understanding the epigenetic contribution to DN progression.

\section{Proteomics Studies in DN}

The proteome probably represents the most complete expression of the potentialities of a living organism since it focuses on the set of proteins, expressed by the genome, that regulate biological and metabolic cell function. The "proteomics," formally defined as the massive and mass spectrometric-based analysis of the proteome, is a complex and interdisciplinary matter requiring expertise spanning from chemistry to biology and bioinformatics, in order to reveal the meaning of complex protein datasets of a biological sample in physiological and pathological conditions. Unlike 
genomics studies, based on the analysis of biological samples that may be expanded artificially making complex studies from little starting material possible, proteomics requires a larger amount of starting sample that can be easily available in biological fluids rather than in the tissues or cells. For this reason, proteomic studies in nephrology are more oriented to the analysis of biological fluids and have led, in the last decade, to the identification of a number of putative biomarkers that are expected to enter shortly into the clinical practice [118].

In the next paragraphs we will discuss the main application of proteomics to the identification of new potential biomarkers of DN in kidney tissues and biological fluids with a special emphasis on the new emerging potentialities of the post-translational modifications (PTMs) screenings. The proteomic markers discussed in this paper are also reported in Table 5.

5.1. Kidney Tissue. Glomerular damage plays a critical role in the onset of DN making this renal compartment a key target for proteomic investigation [119]. However, only few proteomic studies have been carried out on isolated glomeruli since, in general, renal biopsy is rarely carried out on diabetics patients and the number of isolated glomeruli, when starting form biopsy material, is too scarce to produce homogeneous preparations of individual specimens and to extract adequate glomerular protein amounts for deep proteomic studies. Recent methodological improvements [120] have now permitted the extraction of intact and unmodified proteins from formalin fixed paraffin embedded (FFPE) samples thus making available the use of vast archive of kidney tissues for proteomic analysis. Proteomic analysis of isolated glomeruli, obtained by Laser Capture Microdissection (LCM) [121], allowed the identification of over 100 differentially expressed tissue proteins between DN and nondiabetic glomeruli [79]. Notably, the results of this study probably underestimates the differences of the glomerular proteome since it was carried out on FFPE tissues derived from autopsy cases undergoing postmortem proteolysis [122]. However, among differently expressed proteins, nephronectin, a protein implicated in the assembly of extracellular matrix and nephrogenesis [123], was confirmed as differently expressed in DN tissue specimens using immunohistochemistry. A similar study reported increased expression of $\mathrm{C} 3$ and the membrane attack complex (C5b-9) and a marked reduction of podocyte-associated proteins and antioxidant proteins in DN [80]. Even if these proof of concept studies demonstrate the usefulness of FFPE tissue proteomics, the potentialities of this approach are still prevented by the poor availability of tissue specimens that limits the identification of the key molecular events involved in the onset and progression of DN.

5.2. Biofluids. Biofluids encompass any liquid originating from inside the bodies of living organism. Among the body fluids proteomics has been mostly applied to urine and serum/plasma. Rossing and colleagues reported, in urine of T1D patients with $\mathrm{DN}$, a panel of 65 urine biomarkers, mainly composed of collagen fragments, that was further validated in a multicentre independent cohort of T2DM patients $[124,125]$. Zürbig et al. expanded the 65 peptides classifier to 273 and demonstrated its ability to predict the occurrence of the microalbuminuria in T1D and T2DM normoalbuminuric patients $[126,127]$. These data were recently confirmed in another independent study that specifically identified subsets of urine biomarkers able to predict to the transition from normo- to microalbuminuria or from microto macroalbuminuria [81] indicating that the appearance of collagen fragments in urine of T2DM patients may have both diagnostic and prognostic values. Potential predictive biomarkers have been also described in urine samples of T1 diabetic patients [82]. LC/MS/MS analysis of $22 \mathrm{T1D}$ normoalbuminuric patients developing microalbuminuria after 6 years median follow-up allowed identifying a set of potential predictive biomarkers that were further validated by ELISA assay. Of note, the introduction of these proteomic biomarkers (THP, progranulin, alpha-1-glycoprotein, and clusterin) into the baseline model that included diabetes duration, baseline Albumin Excretion rate (AER), HbAlc, cystatin $\mathrm{C}$, and uric acid improved the prediction of renal function worsening from $84 \%$ to $89 \%$.

Jin et al. used Isobaric Tags for Relative and Absolute Quantification (iTRAQ) and LC/MS/MS to quantify and identify a set of urinary proteins differentially excreted between normoalbuminuric and microalbuminuric T2DM patients. Three protein biomarkers, namely, alpha-1-antitrypsin, alpha1-acid glycoprotein 1, and prostate stem cell antigen, were included in a multiplex assay that was able to correctly classify normoalbuminuric and microalbuminuric T2DM patients with about $92 \%$ accuracy [83].

Dihazi et al. identified and validated, by SELDI-TOF/MS, two mass peaks corresponding to B2-microglobulin and ubiquitin ribosomal fusion protein that were selectively and differently excreted in nephropathic diabetic patients [84]. We further refined this study by selecting only diabetic patients with biopsy-proven Kimmelstiel-Wilson lesions and identifying both urinary B2-microglobulin and free ubiquitin as specific biomarkers of diabetic glomerulosclerosis over other nondiabetic kidney lesions [85]. Although the overall analysis of the urine proteome is up to now the most used way to search for disease-specific biomarkers, the future of this matter will be the analysis of well-purified proteins subfractions since it may provide more detailed information about simplified proteomes and potentially improve the knowledge of specific pathways. Until few years ago, the most useful way to reduce the proteome complexity was the selective antibody-based depletion of the most abundant proteins. In the last few years, the enrichment of post-translationally modified proteins has begun a new strategy to highlight functionally interesting proteins. Two emerging branches in this context are phosphoproteomics and glycoproteomics. Protein phosphorylation is a key player in the regulation of most cell pathways; thus, phosphoproteome screening of urine samples may represent a precious source of information about deregulated cell processes in many kidney diseases including DN. However, up to now, urine phosphoproteome analysis has not been applied yet to soluble proteins in DN and other CKD probably because most of the historical collections of urine samples have not been prepared and 
TABLE 5: Proteomic biomarkers. List of significant protein biomarkers ordered as they are cited in the text. LCM: Laser Capture Microdissection; LC/MS/MS: liquid chromatography coupled to tandem mass spectrometry; IF: immunofluorescence; IHC: immunohistochemistry; SELDI-TOF/MS: Surface Enhanced Laser Desorption Ionization Mass Spectrometry; CE-MS: capillary electrophoresis; 2DE: two-dimensional electrophoresis.

\begin{tabular}{|c|c|c|c|c|c|c|c|}
\hline Protein & Code & Sample & Expression & Assay type & $\begin{array}{l}\text { Diabetes } \\
\text { type }\end{array}$ & $\begin{array}{l}\text { Potential } \\
\text { value of } \\
\text { biomarker }\end{array}$ & References \\
\hline Integrin, alpha 1 & ITGA1 & $\begin{array}{l}\text { FFPE } \\
\text { Kidney }\end{array}$ & Up & $\begin{array}{c}\mathrm{LCM}+ \\
\mathrm{LC} / \mathrm{MS} / \mathrm{MS} ; \mathrm{IHC}\end{array}$ & $\mathrm{T} 2 \mathrm{D}$ & Diagnostic & {$[79]$} \\
\hline Laminin, beta 2 & LAMB2, LAMS & $\begin{array}{l}\text { FFPE } \\
\text { Kidney }\end{array}$ & Up & $\begin{array}{c}\mathrm{LCM}+ \\
\mathrm{LC} / \mathrm{MS} / \mathrm{MS} ; \mathrm{IHC}\end{array}$ & $\mathrm{T} 2 \mathrm{D}$ & Diagnostic & {$[79]$} \\
\hline Nephronectin & $\begin{array}{l}\text { NPNT, EGFL6L, } \\
\text { POEM, and } \\
\text { UNQ295/PRO334 }\end{array}$ & $\begin{array}{l}\text { FFPE } \\
\text { Kidney }\end{array}$ & $\mathrm{Up}$ & $\begin{array}{c}\mathrm{LCM}+ \\
\mathrm{LC} / \mathrm{MS} / \mathrm{MS} ; \mathrm{IHC}\end{array}$ & $\mathrm{T} 2 \mathrm{D}$ & Diagnostic & [79] \\
\hline Actinin, alpha 4 & ACTN4 & $\begin{array}{l}\text { FFPE } \\
\text { Kidney }\end{array}$ & Up & $\begin{array}{c}\mathrm{LCM}+ \\
\mathrm{LC} / \mathrm{MS} / \mathrm{MS} ; \mathrm{IHC}\end{array}$ & $\mathrm{T} 2 \mathrm{D}$ & Diagnostic & {$[79]$} \\
\hline $\mathrm{C} 3$ & C3, CPAMD1 & $\begin{array}{l}\text { FFPE } \\
\text { Kidney }\end{array}$ & Up & $\begin{array}{c}\mathrm{LCM}+ \\
\mathrm{LC} / \mathrm{MS} / \mathrm{MS} ; \mathrm{IF}\end{array}$ & $\mathrm{T} 2 \mathrm{D}$ & Diagnostic & {$[80]$} \\
\hline C5b-9 & C5, CPAMD4 & $\begin{array}{c}\text { FFPE } \\
\text { Kidney }\end{array}$ & $\mathrm{Up}$ & $\begin{array}{c}\mathrm{LCM}+ \\
\mathrm{LC} / \mathrm{MS} / \mathrm{MS} ; \mathrm{IF}\end{array}$ & $\mathrm{T} 2 \mathrm{D}$ & Diagnostic & {$[80]$} \\
\hline Fibrinogen $\alpha$-chain & FGA & $\begin{array}{c}\text { FFPE } \\
\text { Kidney }\end{array}$ & Up & $\begin{array}{c}\mathrm{LCM}+ \\
\mathrm{LC} / \mathrm{MS} / \mathrm{MS} ; \mathrm{IF}\end{array}$ & $\mathrm{T} 2 \mathrm{D}$ & Diagnostic & {$[80]$} \\
\hline Synaptopodin & SYNPO, KIAA1029 & $\begin{array}{l}\text { FFPE } \\
\text { Kidney }\end{array}$ & Up & $\begin{array}{c}\mathrm{LCM}+ \\
\mathrm{LC} / \mathrm{MS} / \mathrm{MS} ; \mathrm{IF}\end{array}$ & $\mathrm{T} 2 \mathrm{D}$ & Diagnostic & {$[80]$} \\
\hline $\begin{array}{l}\text { Collagen } \alpha-1 \text { (I) } \\
\text { chain }\end{array}$ & CO1A1_HUMAN & Urine & Down & CE-MS & $\mathrm{T} 2 \mathrm{D}$ & Prognostic & {$[81]$} \\
\hline $\begin{array}{l}\text { Collagen } \alpha-1 \text { (III) } \\
\text { chain }\end{array}$ & CO3A1_HUMAN & Urine & Down & CE-MS & $\mathrm{T} 2 \mathrm{D}$ & Prognostic & {$[81]$} \\
\hline $\begin{array}{l}\text { Collagen } \alpha-2 \text { (I) } \\
\text { chain }\end{array}$ & CO1A2_HUMAN & Urine & Down & CE-MS & $\mathrm{T} 2 \mathrm{D}$ & Prognostic & {$[81]$} \\
\hline $\begin{array}{l}\text { Neurosecretory } \\
\text { protein VGF }\end{array}$ & VGF_HUMAN & Urine & Down & CE-MS & $\mathrm{T} 2 \mathrm{D}$ & Prognostic & {$[81]$} \\
\hline Osteopontin & OSTP_HUMAN & Urine & Down & CE-MS & $\mathrm{T} 2 \mathrm{D}$ & Prognostic & {$[81]$} \\
\hline $\begin{array}{l}\text { Polymeric } \\
\text { immunoglobulin } \\
\text { receptor }\end{array}$ & PIGR_HUMAN & Urine & Down & CE-MS & $\mathrm{T} 2 \mathrm{D}$ & Prognostic & {$[81]$} \\
\hline Serum albumin & ALBU_HUMAN & Urine & Up & CE-MS & $\mathrm{T} 2 \mathrm{D}$ & Prognostic & {$[81]$} \\
\hline $\begin{array}{l}\text { Sodium/potassium- } \\
\text { transporting ATPase } \\
\gamma \text { chain }\end{array}$ & ATNG_HUMAN & Urine & Down & CE-MS & $\mathrm{T} 2 \mathrm{D}$ & Prognostic & {$[81]$} \\
\hline Pro-SAAS & PCSK1_HUMAN & Urine & Up & CE-MS & $\mathrm{T} 2 \mathrm{D}$ & Prognostic & {$[81]$} \\
\hline $\begin{array}{l}\alpha \text {-2-HS- } \\
\text { glycoprotein }\end{array}$ & FETUA_HUMAN & Urine & Up & CE-MS & $\mathrm{T} 2 \mathrm{D}$ & Prognostic & {$[81]$} \\
\hline a-1 acid glycoprotein & AGP & Urine & Up & $\begin{array}{l}\text { SDS-PAGE + } \\
\text { LC/MS/MS + } \\
\text { ELISA }\end{array}$ & T1D & Prognostic & {$[82]$} \\
\hline Clusterin & $\begin{array}{l}\text { CLU, APOJ, CLI, } \\
\text { KUB1, and AAG4 }\end{array}$ & Urine & Comparable & $\begin{array}{l}\text { SDS-PAGE + } \\
\text { LC/MS/MS + } \\
\text { ELISA }\end{array}$ & T1D & Prognostic & {$[82]$} \\
\hline Progranulin & GRN & Urine & Up & $\begin{array}{l}\text { SDS-PAGE + } \\
\text { LC/MS/MS + } \\
\text { ELISA }\end{array}$ & T1D & Prognostic & {$[82]$} \\
\hline $\begin{array}{l}\text { Tamms-Horsfall } \\
\text { glycoprotein }\end{array}$ & THP & Urine & Up & $\begin{array}{c}\text { SDS-PAGE + } \\
\text { LC/MS/MS + } \\
\text { ELISA }\end{array}$ & $\mathrm{T} 1 \mathrm{D}$ & Prognostic & {$[82]$} \\
\hline $\begin{array}{l}\text { Alpha-1-acid } \\
\text { glycoprotein } 1\end{array}$ & ORM1, AGP1 & Urine & Up & $\begin{array}{l}\text { iTRAQ labelling + } \\
\text { LC-MS/MS; WB }\end{array}$ & $\mathrm{T} 2 \mathrm{D}$ & Diagnostic & {$[83]$} \\
\hline
\end{tabular}


TABLe 5: Continued.

\begin{tabular}{|c|c|c|c|c|c|c|c|}
\hline Protein & Code & Sample & Expression & Assay type & $\begin{array}{l}\text { Diabetes } \\
\text { type }\end{array}$ & $\begin{array}{c}\text { Potential } \\
\text { value of } \\
\text { biomarker }\end{array}$ & References \\
\hline Alpha-1-antitrypsin & $\begin{array}{l}\text { SERPINA1, AAT, } \\
\text { PI, PRO0684, and } \\
\text { PRO2209 }\end{array}$ & Urine & Up & $\begin{array}{l}\text { iTRAQ labelling + } \\
\text { LC-MS/MS; WB }\end{array}$ & $\mathrm{T} 2 \mathrm{D}$ & Diagnostic & {$[83]$} \\
\hline $\begin{array}{l}\text { Prostate stem cell } \\
\text { antigen }\end{array}$ & $\begin{array}{c}\text { PSCA, } \\
\text { UNQ206/PRO232 }\end{array}$ & Urine & Up & $\begin{array}{l}\text { iTRAQ labelling + } \\
\text { LC-MS/MS; WB }\end{array}$ & $\mathrm{T} 2 \mathrm{D}$ & Diagnostic & {$[83]$} \\
\hline $\begin{array}{l}\text { Ubiquitin ribosomal } \\
\text { fusion protein } \\
\text { (UbA52) }\end{array}$ & UBA52, UBCEP2 & Urine & Up & $\begin{array}{c}\text { SELDI-TOF/MS, } \\
\text { WB }\end{array}$ & $\mathrm{T} 2 \mathrm{D}$ & Diagnostic & {$[84]$} \\
\hline$\beta 2$-microglobulin & $\begin{array}{l}\text { B2M, CDABP0092, } \\
\text { and HDCMA22P }\end{array}$ & Urine & Up & $\begin{array}{l}\text { SELDI-TOF/MS, } \\
\text { WB, ELISA }\end{array}$ & $\mathrm{T} 2 \mathrm{D}$ & Diagnostic & {$[84,85]$} \\
\hline Free ubiquitin & $\begin{array}{l}\text { UBB, UBC, } \\
\text { UBA52, and } \\
\text { RPS27A }\end{array}$ & Urine & Up & $\begin{array}{l}\text { SELDI-TOF/MS, } \\
\text { WB, ELISA }\end{array}$ & $\mathrm{T} 2 \mathrm{D}$ & Diagnostic & {$[85]$} \\
\hline $\begin{array}{l}\text { Histone-lysine } \\
\mathrm{N} \text {-methyltransferase } \\
\text { 2C }\end{array}$ & $\begin{array}{l}\text { KMT2C, HALR, } \\
\text { KIAA1506, and } \\
\text { MLL3 }\end{array}$ & $\begin{array}{c}\text { Urine } \\
\text { exosomes }\end{array}$ & Up & $2 \mathrm{DE}+\mathrm{LC} / \mathrm{MS} / \mathrm{MS}$ & $\mathrm{T} 2 \mathrm{D}$ & Diagnostic & {$[86]$} \\
\hline $\begin{array}{l}\text { Voltage-dependent } \\
\text { anion-selective } \\
\text { channel protein } 1\end{array}$ & VDAC1, VDAC & $\begin{array}{c}\text { Urine } \\
\text { exosomes }\end{array}$ & Down & $2 \mathrm{DE}+\mathrm{LC} / \mathrm{MS} / \mathrm{MS}$ & $\mathrm{T} 2 \mathrm{D}$ & Diagnostic & {$[86]$} \\
\hline $\begin{array}{l}\text { Alpha-1- } \\
\text { microglobulin/ } \\
\text { bikunin precursor }\end{array}$ & $\begin{array}{c}\text { AMBP, HCP, and } \\
\text { ITIL }\end{array}$ & $\begin{array}{l}\text { Urine } \\
\text { exosomes }\end{array}$ & Up & $2 \mathrm{DE}+\mathrm{LC} / \mathrm{MS} / \mathrm{MS}$ & $\mathrm{T} 2 \mathrm{D}$ & Diagnostic & {$[86]$} \\
\hline Vasorin (glycated) & $\begin{array}{c}\text { VASN, SLITL2, } \\
\text { UNQ314/PRO357/ } \\
\text { PRO1282 }\end{array}$ & Plasma & Up & LC/MS/MS; WB & $\mathrm{T} 2 \mathrm{D}$ & Diagnostic & {$[87]$} \\
\hline $\begin{array}{l}\text { Retinol binding } \\
\text { protein-4 (glycated) }\end{array}$ & $\begin{array}{l}\text { RBP4, and } \\
\text { PRO2222 }\end{array}$ & Plasma & $\mathrm{Up}$ & LC/MS/MS; WB & $\mathrm{T} 2 \mathrm{D}$ & Diagnostic & {$[87]$} \\
\hline Lumican (glycated) & $\begin{array}{l}\text { LUM, LDC, } \\
\text { SLRR2D }\end{array}$ & Plasma & Up & LC/MS/MS; WB & $\mathrm{T} 2 \mathrm{D}$ & Diagnostic & {$[87]$} \\
\hline Vasorin (glycated) & $\begin{array}{c}\text { VASN, SLITL2, } \\
\text { and } \\
\text { UNQ314/PRO357/ } \\
\text { PRO1282 }\end{array}$ & Plasma & Up & LC/MS/MS; WB & $\mathrm{T} 2 \mathrm{D}$ & Diagnostic & [87] \\
\hline $\begin{array}{l}\text { Hemopexin } \\
\text { precursor (glycated) }\end{array}$ & MMP15 & Plasma & Up & $\begin{array}{l}\text { 2DE; ESI-Q- } \\
\text { TOF/MS/MS }\end{array}$ & $\mathrm{T} 2 \mathrm{D}$ & Diagnostic & {$[88]$} \\
\hline $\begin{array}{l}\text { Alpha-1-antitrypsin } \\
\text { (glycated) }\end{array}$ & $\begin{array}{l}\text { SERPINA1, AAT, } \\
\text { PI, PRO0684, and } \\
\text { PRO2209 }\end{array}$ & Plasma & Up & $\begin{array}{l}\text { 2DE; ESI-Q- } \\
\text { TOF/MS/MS }\end{array}$ & $\mathrm{T} 2 \mathrm{D}$ & Diagnostic & {$[88]$} \\
\hline $\begin{array}{l}\text { Haptoglobin-related } \\
\text { protein (glycated) }\end{array}$ & HPR & Plasma & Up & $\begin{array}{l}\text { 2DE; ESI-Q- } \\
\text { TOF/MS/MS }\end{array}$ & $\mathrm{T} 2 \mathrm{D}$ & Diagnostic & {$[88]$} \\
\hline $\begin{array}{l}\text { Serine proteinase } \\
\text { inhibitor (glycated) }\end{array}$ & $\begin{array}{l}\text { SERPINA5, PCI, } \\
\text { PLANH3, and } \\
\text { PROCI }\end{array}$ & Plasma & Up & $\begin{array}{l}\text { 2DE; ESI-Q- } \\
\text { TOF/MS/MS }\end{array}$ & $\mathrm{T} 2 \mathrm{D}$ & Diagnostic & {$[88]$} \\
\hline $\begin{array}{l}\text { Complement factor } \\
\text { C4B3 (glycated) }\end{array}$ & $\begin{array}{c}\text { C4B, CO4, } \\
\text { CPAMD3, and } \\
\text { C4B_2 }\end{array}$ & Plasma & Up & $\begin{array}{l}\text { 2DE; ESI-Q- } \\
\text { TOF/MS/MS }\end{array}$ & $\mathrm{T} 2 \mathrm{D}$ & Diagnostic & {$[88]$} \\
\hline $\begin{array}{l}\text { Prekallikrein } \\
\text { (glycated) }\end{array}$ & KLKB1, KLK3 & Plasma & Up & $\begin{array}{l}\text { 2DE; ESI-Q- } \\
\text { TOF/MS/MS }\end{array}$ & $\mathrm{T} 2 \mathrm{D}$ & Diagnostic & {$[88]$} \\
\hline $\begin{array}{l}\text { Apolipoprotein } \\
\text { (ApoE) }\end{array}$ & $\mathrm{APOE}$ & Plasma & Up & $\begin{array}{l}\text { 2DE; MALDI- } \\
\text { TOF/MS/MS }\end{array}$ & $\mathrm{T} 2 \mathrm{D}$ & Diagnostic & [89] \\
\hline $\begin{array}{l}\text { Glutathione } \\
\text { peroxidase (eGPx) }\end{array}$ & GPX2 & Plasma & Up & $\begin{array}{l}\text { 2DE; MALDI- } \\
\text { TOF/MS/MS }\end{array}$ & $\mathrm{T} 2 \mathrm{D}$ & Diagnostic & [89] \\
\hline $\begin{array}{l}\text { Vitamin D-binding } \\
\text { protein }(\mathrm{DBP})\end{array}$ & GC & Plasma & Up & $\begin{array}{l}\text { 2DE; MALDI- } \\
\text { TOF/MS/MS }\end{array}$ & $\mathrm{T} 2 \mathrm{D}$ & Diagnostic & [89] \\
\hline
\end{tabular}


stored in presence of phosphatases inhibitors that, preventing the liability of this PTMs, may ensure more reproducible results. On the contrary, the analysis of the microvesicular fraction (i.e., exosomes) that originates from renal epithelial cells and are released into urine may be, at the moment, more useful to study this kind of PTM as the presence of the exosomes' membrane may preserve PTMs by protecting their protein content from spontaneous degradation and dephosphorylation by proteases or phosphatases, respectively [128]. Zubiri et al. have already published the first proteomic study on urine exosomes of DN patients demonstrating the potentiality of this microvesicular screening for identifying DN specific biomarkers [86]. Specifically, 3 over the 25 most significant differently expressed proteins, namely, voltagedependent anion-selective channel protein 1 (VDAC1), Isoform 1 of histone-lysine N-methyltransferase MLL3, and alpha-1-microglobulin/bikunin precursor (AMB), were also validated. Of note, MLL3, a specific tag for epigenetic transcriptional activation, was detected only in DN exosomes, thus emphasizing the potential importance of epigenetic mechanisms in the pathophysiology of DN. Furthermore, Gonzales et al. have recently reported the first phosphoproteomic screening of the urine exosomes in healthy subjects [129]. It is reasonable to think about the forthcoming application of the exosomes' phosphoproteomics as a new way to identify specific deregulated patterns in kidney diseases. As for phosphoproteomics also glycoproteomics of urine samples is in its infancy. At the moment, only one paper has applied this approach to the study of CKD identifying a number of urinary proteins involved in immune/stress response and many biological functions like homeostasis, platelet degranulation and coagulation, transport, and secretion [130]. Due to the importance of the glycoproteomics in cell-cell interaction and signalling cascades, it is reasonable that many further studies will be planned in the next year to understand, by screening this specific subset of proteins, the molecular mechanisms involved in damage progression of specific nephropathies including DN. Interestingly, the usefulness of the glycoproteomics for the diagnosis of DN has been recently reported in plasma where thirteen significantly upregulated glycoproteins were described in DN patients compared to T2DM patients without nephropathy [87]. Among these, increased plasma levels of glycated lumican, vasorin, and retinol binding protein- 4 were validated by immunoblotting and showed potential specificity for DN. By using a different proteomic strategy, Kim and coworkers reported that increased plasma levels of glycated PEDF, apolipoprotein J precursor, hemopexin, immunoglobulin mu heavy chain, and immunoglobulin kappa chain correlated with poor glycaemic control in T2DM patients while glycated prekallikrein and complement factor C4B3 correlated with microalbuminuria and other glycated proteins such as hemopexin precursor, serine proteinase inhibitor, alpha-1antitrypsin, and haptoglobin-related protein were associated with DN [88]. These studies confirmed the potentiality of the plasma glycoproteome for the identification of reliable biomarkers of DN and their importance is emphasized by the consideration that the overall analysis of serum/plasma proteome is challenging because the candidate biomarkers are generally present in trace amounts. Of note, there is an alternative way to reduce the complexity of this biological fluid, namely, the prefractionation of the samples, achieved by several known strategies before the analysis [131], that allow removing the large background of nonrelevant and abundant proteins and may favour the discovery of potential candidate biomarkers. Up to now only few studies have used this approach to analyse the serum $[89,132]$ or plasma [133] proteome of T2DM patients. These studies have reported extracellular glutathione peroxidase (eGPx) and apolipoprotein (ApoE) as potential diagnostic biomarkers of DN and vitamin $\mathrm{D}$-binding protein (DBP) as early biomarker of renal damage in T2DM. Overall many independent studies are showing an increasing number of new biomarkers that are potentially useful for both early diagnosis and monitoring of the disease and to understand ever more deeply its pathogenesis.

\section{Metabolomics Studies on DN}

Metabolomics is a systematic evaluation of small molecules (i.e., metabolites) that may provide fundamental biochemical insights into disease pathways, drug toxicity, and gene function. Metabolomics profiling is generally carried out by Nuclear Magnetic Resonance (NMR) and MS-based profiling each with advantage and limitations [134]. Two main strategies may be adopted for metabolomics analysis of biological samples: targeted and untargeted profiling. The targeted profiling focuses only on sets of few metabolites generally included in specific metabolic pathways while untargeted analysis provides a comprehensive evaluation of the metabolome without any a priori hypothesis on the metabolic pathways. Targeted analysis is an essential tool for the investigation of biological mechanisms rather than for biomarkers discovery; in fact it is a quantitative approach that allows quantification of each metabolite of an interested metabolic pathway through the use of isotope-labelled standards [135]. Untargeted approach is instead more suitable for biomarker discovery since the whole metabolic profile of cases and controls may allow identification of diseasecorrelated biomarkers. As obvious, the latter approach needs, as for proteomics, further data analysis through supervised statistical methods in order to construct disease-specific metabolomics classifier further sequenced by mass spectrometry. In the last years, the optimization of the separation techniques has allowed the selectively purification of specific class of metabolites such as phospholipids and fatty acids, leading to the development of new more focused untargeted analysis such as "phospholipidomics." As for proteomics, most of the metabolomics studies have been carried out on biofluids, namely, urine and serum/plasma. All metabolomic markers cited in this paper are also reported in Table 6.

6.1. Urine Metabolomics. Urine metabolomics may offer direct insights into biochemical pathways linked to kidney dysfunction since a variety of metabolites are concentrated by the kidney and excreted in urine. Sharma et al. [90] used targeted analysis to investigate the urinary excretion of 94 metabolites in healthy subjects (HS) and T2DM patients with $(\mathrm{DM}+\mathrm{CKD})$ or without (DM-CKD) CKD. Thirteen 
TABLE 6: Metabolomics biomarkers. List of significant metabolites ordered as they are cited in the text. LC/MS/MS: liquid chromatography coupled to tandem mass spectrometry; GC-MS: gas chromatography/mass spectrometry; NMR: Nuclear Magnetic Resonance; CE-MS: capillary electrophoresis; HPLC-UV/MS/MS: high pressure liquid chromatography coupled to UV and mass spectrometry; UPLC-oa-TOFMS: ultra performance liquid chromatography coupled to time of flight mass spectrometry.

\begin{tabular}{|c|c|c|c|c|c|c|c|}
\hline Metabolite & Code & Sample & Expression & Assay type & Diabetes type & $\begin{array}{c}\text { Potential } \\
\text { value of } \\
\text { biomarker }\end{array}$ & References \\
\hline 2-Methyl acetoacetate & HMDB03771 & Urine & Down & GC-MS & $\mathrm{T} 2 \mathrm{D}$ & Diagnostic & {$[90]$} \\
\hline 3-Methyl adipic acid & HMDB00555 & Urine & Down & GC-MS & $\mathrm{T} 2 \mathrm{D}$ & Diagnostic & {$[90]$} \\
\hline $\begin{array}{l}\text { 3-Methyl crotonyl } \\
\text { glycine }\end{array}$ & HMDB00459 & Urine & Down & GC-MS & $\mathrm{T} 2 \mathrm{D}$ & Diagnostic & {$[90]$} \\
\hline 2-Ethyl 3-OH propionate & HMDB00396 & Urine & Down & GC-MS & $\mathrm{T} 2 \mathrm{D}$ & Diagnostic & {$[90]$} \\
\hline 3-Hydroxyisobutyrate & HMDB00435 & Urine & Down & GC-MS & $\mathrm{T} 2 \mathrm{D}$ & Diagnostic & {$[90]$} \\
\hline 3-Hydroxyisovalerate & HMDB00754 & Urine & Down & GC-MS & $\mathrm{T} 2 \mathrm{D}$ & Diagnostic & {$[90]$} \\
\hline 3-Hydroxypropionate & HMDB00700 & Urine & Down & GC-MS & $\mathrm{T} 2 \mathrm{D}$ & Diagnostic & {$[90]$} \\
\hline Aconitic acid & HMDB00958 & Urine & Down & GC-MS & $\mathrm{T} 2 \mathrm{D}$ & Diagnostic & {$[90]$} \\
\hline Citric acid & HMDB00094 & Urine & Down & GC-MS & $\mathrm{T} 2 \mathrm{D}$ & Diagnostic & {$[90]$} \\
\hline Glycolic acid & HMDB00115 & Urine & Down & GC-MS & $\mathrm{T} 2 \mathrm{D}$ & Diagnostic & {$[90]$} \\
\hline Homovanillic acid & HMDB00118 & Urine & Down & GC-MS & $\mathrm{T} 2 \mathrm{D}$ & Diagnostic & {$[90]$} \\
\hline Tiglylglycine & HMDB00959 & Urine & Down & GC-MS & $\mathrm{T} 2 \mathrm{D}$ & Diagnostic & {$[90]$} \\
\hline Uracil & HMDB00300 & Urine & Down & GC-MS & $\mathrm{T} 2 \mathrm{D}$ & Diagnostic & {$[90]$} \\
\hline Butenoylcarnitine & HMDB13126 & Plasma & Up & GC-MS & $\mathrm{T} 2 \mathrm{D}$ & Prognostic & {$[91]$} \\
\hline Glutamine & HMDB00641 & Urine & Down & GC-MS & $\mathrm{T} 2 \mathrm{D}$ & Prognostic & {$[91]$} \\
\hline Hexose & HMDB33704 & Urine & Down & GC-MS & $\mathrm{T} 2 \mathrm{D}$ & Prognostic & {$[91]$} \\
\hline Histidine & HMDB00177 & Plasma & Down & GC-MS & $\mathrm{T} 2 \mathrm{D}$ & Prognostic & {$[91]$} \\
\hline Tyrosine & HMDB00158 & Urine & Down & GC-MS & $\mathrm{T} 2 \mathrm{D}$ & Prognostic & {$[91]$} \\
\hline Hippuric acid & HMDB00714 & Urine & Down & LC-MS & T1D & Prognostic & {$[92]$} \\
\hline $\begin{array}{l}\text { S-(3-Oxododecanoyl) } \\
\text { cysteamine }\end{array}$ & HMDB59773 & Urine & Up & LC-MS & T1D & Prognostic & {$[92]$} \\
\hline Substituted carnitine & HMDB00062 & Urine & $\mathrm{Up}$ & LC-MS & T1D & Prognostic & {$[92]$} \\
\hline 3-OH-isovalerate & HMDB00754 & Serum & Down & NMR & $\mathrm{T} 2 \mathrm{D}$ & Diagnostic & [93] \\
\hline $\begin{array}{l}\text { 4-Aminobutyrate + } \\
(\mathrm{CH}-\mathrm{CH} 2-\mathrm{CH} 2-)\end{array}$ & HMDB00112 & Serum & Up & NMR & $\mathrm{T} 2 \mathrm{D}$ & Diagnostic & [93] \\
\hline Alanine & HMDB00161 & Serum & Down & NMR & $\mathrm{T} 2 \mathrm{D}$ & Diagnostic & [93] \\
\hline Cholesterol & HMDB00067 & Serum & Down & NMR & $\mathrm{T} 2 \mathrm{D}$ & Diagnostic & {$[93]$} \\
\hline Choline & HMDB00097 & Serum & Down & NMR & $\mathrm{T} 2 \mathrm{D}$ & Diagnostic & {$[93]$} \\
\hline Creatine & HMDB00064 & Serum & Down & NMR & $\mathrm{T} 2 \mathrm{D}$ & Diagnostic & {$[93]$} \\
\hline Creatine-P & HMDB01511 & Serum & Down & NMR & $\mathrm{T} 2 \mathrm{D}$ & Diagnostic & {$[93]$} \\
\hline Creatinine & HMDB00562 & Serum & $\mathrm{Up}$ & NMR & $\mathrm{T} 2 \mathrm{D}$ & Diagnostic & {$[93]$} \\
\hline Dimethylamine & HMDB00087 & Serum & Down & NMR & $\mathrm{T} 2 \mathrm{D}$ & Diagnostic & [93] \\
\hline Glucose & HMDB00122 & Serum & $\mathrm{Up}$ & NMR & $\mathrm{T} 2 \mathrm{D}$ & Diagnostic & {$[93]$} \\
\hline Glutamine & HMDB00641 & Serum & Down & NMR & $\mathrm{T} 2 \mathrm{D}$ & Diagnostic & {$[93]$} \\
\hline Isoleucine & HMDB00172 & Serum & Down & NMR & $\mathrm{T} 2 \mathrm{D}$ & Diagnostic & [93] \\
\hline Isoleucine & HMDB00172 & Serum & Down & NMR & $\mathrm{T} 2 \mathrm{D}$ & Diagnostic & [93] \\
\hline Lactate & HMDB00190 & Serum & $\mathrm{Up}$ & NMR & $\mathrm{T} 2 \mathrm{D}$ & Diagnostic & {$[93]$} \\
\hline Leucine & HMDB00687 & Serum & $\mathrm{Up}$ & NMR & $\mathrm{T} 2 \mathrm{D}$ & Diagnostic & {$[93]$} \\
\hline Leucine + isoleucine & HMDB28932 & Serum & Down & NMR & $\mathrm{T} 2 \mathrm{D}$ & Diagnostic & {$[93]$} \\
\hline Lipid (-CH3) & - & Serum & $\mathrm{Up}$ & NMR & $\mathrm{T} 2 \mathrm{D}$ & Diagnostic & {$[93]$} \\
\hline Lipids (beta-CH2) & - & Serum & Up & NMR & $\mathrm{T} 2 \mathrm{D}$ & Diagnostic & {$[93]$} \\
\hline Lipids (CH2-)n & - & Serum & $\mathrm{Up}$ & NMR & $\mathrm{T} 2 \mathrm{D}$ & Diagnostic & {$[93]$} \\
\hline $\mathrm{N}$-Acetylglutamine & HMDB06029 & Serum & Down & NMR & $\mathrm{T} 2 \mathrm{D}$ & Diagnostic & {$[93]$} \\
\hline
\end{tabular}


TABle 6: Continued.

\begin{tabular}{|c|c|c|c|c|c|c|c|}
\hline Metabolite & Code & Sample & Expression & Assay type & Diabetes type & $\begin{array}{c}\text { Potential } \\
\text { value of } \\
\text { biomarker }\end{array}$ & References \\
\hline O-Phosphocholine & HMDB01565 & Serum & Down & NMR & T2D & Diagnostic & [93] \\
\hline Proline & HMDB00162 & Serum & Down & NMR & $\mathrm{T} 2 \mathrm{D}$ & Diagnostic & [93] \\
\hline Pyruvate & HMDB00243 & Serum & Down & NMR & $\mathrm{T} 2 \mathrm{D}$ & Diagnostic & [93] \\
\hline Trimethylamine & HMDB00906 & Serum & Down & NMR & $\mathrm{T} 2 \mathrm{D}$ & Diagnostic & [93] \\
\hline Valine & HMDB00883 & Serum & Down & NMR & $\mathrm{T} 2 \mathrm{D}$ & Diagnostic & [93] \\
\hline Valine + isoleucine & HMDB29130 & Serum & Down & NMR & $\mathrm{T} 2 \mathrm{D}$ & Diagnostic & [93] \\
\hline Aspartic acid & HMDB00191 & Serum & Up & CE-MS & $\mathrm{T} 2 \mathrm{D}$ & Diagnostic & [94] \\
\hline Azelaic acid & HMDB00784 & Serum & Down & CE-MS & $\mathrm{T} 2 \mathrm{D}$ & Diagnostic & [94] \\
\hline Galactaric acid & HMDB00639 & Serum & Down & CE-MS & $\mathrm{T} 2 \mathrm{D}$ & Diagnostic & [94] \\
\hline $\begin{array}{l}\text { Symmetric } \\
\text { dimethylarginine } \\
\text { (SDMA) }\end{array}$ & HMDB03334 & Serum & Up & CE-MS & $\mathrm{T} 2 \mathrm{D}$ & Diagnostic & [94] \\
\hline Dihydrosphingosine & HMDB00269 & Serum & Down & UPLC-oa-TOF-MS & $\mathrm{T} 2 \mathrm{D}$ & Diagnostic & [95] \\
\hline Leucine & HMDB00687 & Serum & Down & UPLC-oa-TOF-MS & $\mathrm{T} 2 \mathrm{D}$ & Diagnostic & [95] \\
\hline Phytosphingosine & HMDB04610 & Serum & Down & UPLC-oa-TOF-MS & $\mathrm{T} 2 \mathrm{D}$ & Diagnostic & [95] \\
\hline Adenosine & HMDB00050 & Plasma & Up & HPLC-UV/MS/MS & $\mathrm{T} 2 \mathrm{D}$ & Diagnostic & [96] \\
\hline Creatinine & HMDB00562 & Plasma & Up & HPLC-UV/MS/MS & $\mathrm{T} 2 \mathrm{D}$ & Diagnostic & {$[96]$} \\
\hline Inosine & HMDB00195 & Plasma & Down & HPLC-UV/MS/MS & $\mathrm{T} 2 \mathrm{D}$ & Diagnostic & [96] \\
\hline Uric acid & HMDB00289 & Plasma & Up & HPLC-UV/MS/MS & $\mathrm{T} 2 \mathrm{D}$ & Diagnostic & [96] \\
\hline Xanthine & HMDB00292 & Plasma & $\mathrm{Up}$ & HPLC-UV/MS/MS & $\mathrm{T} 2 \mathrm{D}$ & Diagnostic & [96] \\
\hline Phosphatidylinositol & HMDB06953 & Plasma & Down & LC/MS/MS & $\mathrm{T} 2 \mathrm{D}$ & Diagnostic & [97] \\
\hline Sphingomyelin & HMDB12089 & Plasma & Up & $\mathrm{LC} / \mathrm{MS} / \mathrm{MS}$ & $\mathrm{T} 2 \mathrm{D}$ & Diagnostic & [97] \\
\hline Arachidonic acid & HMDB01043 & Plasma & Up & CG-MS & $\mathrm{T} 2 \mathrm{D}$ & Prognostic & [98] \\
\hline
\end{tabular}

metabolites differently excreted between T2DM patients and HS were also useful to differentiate DM+CKD from DMCKD. Interestingly, 5 out 13 metabolites were differently excreted between DN and other CKD, thus being specifically associated with the diabetic kidney disease while 8/13 reflected metabolic changes shared by diabetic and nondiabetic CKD. Most of the less excreted metabolites in DN group were water soluble organic anions and functional analysis correlated them with impaired mitochondrial function in DN. Very recently, Pena and colleagues carried out an untargeted analysis of urine and plasma metabolome by GC-MS and reported the possible usefulness of a set of metabolites to predict the development of DN on top of the traditional renal risk markers, namely, baseline urinary albumin excretion and baseline estimated glomerular filtration rate [91]. In this prospective study, 24 normo- to microalbuminuria case/controls pairs and 21 micro- to macroalbuminuria case/controls pairs were enrolled. The metabolomic profiles of micro- to macroalbuminuria case/control pairs show significant differences while normo- to microalbuminuria pairs remained unchanged. Specifically they reported two plasma metabolites (butenoylcarnitine and histidine) and three urine metabolites (hexose, glutamine, and tyrosine) significantly differentially excreted in microalbuminuric patients prone to develop macroalbuminuria. The area under receiving operating characteristic (ROC) curve arising from the integration of these urine and plasma metabolites to a reference model based on baseline eGFR and urine albumin excretion passed form $84 \%$ to $99 \%$ correct prediction. Although these results appear impressive, as the authors suggest, they still need to be managed with care until a validation study on larger and independent cohorts will be set up. Some of the identified metabolites may have direct link with the pathopysiology of diabetes and its chronic complications since, for example, butenoylcarnitine plasma accumulation has been related to the excessive yet incomplete mitochondrial oxidation of fatty acids [136], possibly attributable to a lower mitochondrial number and reduced oxidation capacity in T2D tissues [137] while histidine, a modulator of inflammation and oxidative stress, may be correlated with impaired inflammation and oxidative stress in T2DM and CKD patients. It is worth noting that both studies stressed the importance of mitochondria dysregulation in the pathogenesis of DN. Urine metabolomics has been also applied to type 1 diabetic patients in order to identify predictive biomarkers of renal function worsening [92]. Metabolite profile of baseline $24 \mathrm{~h}$ urine samples of 52 type 1 diabetic patients (26 stable normoalbuminuric and 26 progressed toward microalbuminuria in 5.5 years' follow-up) was carried out by LC/MS and GCMS. Multivariate logistic regression analysis of GC-MS and LC/MS dataset showed $65 \%$ and $75 \%$ predictive power after cross-validation, respectively. Twenty-one and 14 compounds 
showed a significant contribution to the logistic regression model based on GC-MS and LC/MS dataset, respectively. Most of the identified GC-MS compounds were carboxylic compounds, acidic metabolites, and endogenous amino acids not showing a documented direct relation to DN while LCMS dataset reveals specific compounds related to impaired fatty acids metabolism, detoxification system, and gut microbiome.

6.2. Serum and Plasma Metabolomics. Serum and plasma metabolomics has been carried out of both whole samples and specific subfractions. Marrachelli and coworkers [93] performed both genomic and metabolomic screening of over 1500 Caucasian T2DM patients, characterized the serum metabolome profile of the microalbuminuric patients by Nuclear Magnetic Resonance (NMR), and correlated it with specific genotypes, thus reporting a potential predictive value of the genotype on the onset of microalbuminuria in T2DM. Furthermore, Hirayama et al. [94] reported, in T2DM patients, 19 serum metabolites including creatinine, aspartic acid, $\gamma$-butyrobetaine, citrulline, symmetric dimethylarginine (SDMA), kynurenine, azelaic acid, and galactaric acid that were positively correlated with albuminuria and negatively with eGFR. Of note, some of the most significantly differently excreted metabolites were not identified. Multiple logistic regression, carried out on identified metabolites, recognized 4 features, namely, aspartic acid, azelaic acid, galactaric acid, and symmetric dimethylarginine (SDMA) as relevant for the model and allowed correct identification of DN patients with about 75\% accuracy. Zhang et al. [95] carried out serum metabolomic profiling of $8 \mathrm{DN}$ patients, 33 type 2 diabetes mellitus (T2DM) patients, and 25 healthy volunteers in order to investigate the presence of DN biomarkers. Importantly, they reported significant changes of leucine, dihydrosphingosine and phytoshpingosinewere specifically in the DN cohort, thus suggesting the perturbations of amino acid metabolism and phospholipid metabolism as key events in diabetic disease. Other authors have instead investigated specific subfractions of the metabolome, namely, compounds linked to purine and pyrimidine metabolism, phospholipids, and fatty acids.

Xia et al. [96] standardized an analytical method for analysis and quantification of purine and pyrimidine metabolites in DN patients and matched healthy controls. According to the well-established association of the purine and pyrimidine metabolic pathway with the development of the DN, they could assess that uric acid, xanthine, and adenosine were significantly increased in DN patients (especially in those at stage $\mathrm{V}$ according to Mogensen classification) while inosine is reduced probably as a result of the adenosine deaminase inhibition that catalyzes inosine formation from adenosine. Impaired lipid metabolism has been directly associated with T2DM and DN. Several phospholipids (PLs), significantly upregulated or downregulated in disease models, have been already recognized as potential biomarkers of T2DM or DN [138, 139]. Comprehensive and quantitative analysis of plasma PLs, such as phosphatidylethanolamine, phosphatidylglycerol, phosphatidylcholine, phosphatidylinositol, phosphatidylserine, sphingomyelin, and lysophosphatidylcholine, may selectively distinguish T2DM from DN patients [97]. Targeted quantification of the phospholipids revealed proportional decrease of phosphatidylinositol and linear increase of sphingomyelin in DN patients. Although the molecular pathogenetic mechanisms leading to impaired metabolism of phospholipids are not clear, the authors suggest that reduced phosphatidylinositol may reflect increased sorbitol pathway activation in T2DM while increased sphingomyelin may depend on glucocorticoids-mediated sphingolipids metabolism.

Also plasma fatty acids (FAs) may have a direct impact on the occurrence and development of diabetes since their abnormal accumulation in parenchymal cells of multiple tissues, called lipotoxicity, has been suggested as a trigger of T2DM and its chronic complications [140]. Specific metabolomics screening of FAs, namely, lipidomics, may contribute to the understanding of this disease. Han and colleagues reported a standardized method based on Gas Chromatography-Mass Spectrometry (CG-MS) useful for the specific assessment of nonesterified and esterified fatty acids (NEFAs and EFAs, resp.) [98]. Lipidomics screening of 150 patients including diabetics with and without nephropathy showed high discrimination power on different stage of DN. Disease progression was specifically correlated with plasma levels of arachidonic acid that is involved in the anabolism of prostaglandins, thus suggesting a key role of the inflammatory processes in the progression of $\mathrm{DN}$.

\section{Conclusion}

As genetic studies conducted so far are still inconclusive, it is difficult to envisage a common genetic basis for the development of DN. Quite possibly a number of environmental factors contribute significantly toward the evolution of the diabetic patient to this specific complication. However, there is no doubt that, from the earliest stages of the disease, many molecular changes, observed at the transcriptomics, proteomics, and metabolomics level, anticipate the onset of a clinical phenotype and may allow us to reconstruct in detail the pathogenetic basis of kidney damage in T2DM. Although new omics challenges such as the analysis of the protein posttranslational modifications and of multiprotein complexes, mimicking what naturally happen in intracellular behavior, will further broaden our understanding of the DN pathogenesis, we are already able to identify the common thread that unites all the disparate molecular changes described in the literature by performing bioinformatic-based analysis of genes, transcripts, proteins, and metabolites described so far. We can envisage that the selection of specific omic biomarkers and clinical phenotypes might lead to a better stratification of patient's specific "type" of renal damage in T2DM and might allow the identification of patients that progress or respond to a specific therapy. To accomplish this task and go forward, however, there is an urgent need to build up disease-specific platforms containing personal, clinical, and omics profiles that will allow the full potential application of systems biology analysis and the development of specific disease phenotype models. 
We can expect in the next future the development of new paradigms of renal damage in T2DM that will contribute to defining of the road to the molecular medicine as a global, organized approach applicable to DN as well as to other relevant renal conditions.

\section{Conflict of Interests}

The authors declare that there is no conflict of interests regarding the publication of this paper.

\section{Acknowledgment}

The study was supported by the following grant: Italian Ministry of Health, Ricerca Finalizzata 2009; Project code: RF-2009-1470765, Principal Investigators: Dr. S. De Cosmo and Professor L. Gesualdo.

\section{References}

[1] T. H. Hostetter, H. G. Rennke, and B. M. Brenner, "The case for intrarenal hypertension in the initiation and progression of diabetic and other glomerulopathies," The American Journal of Medicine, vol. 72, no. 3, pp. 375-380, 1982.

[2] Y. S. Kanwar, L. Sun, P. Xie, F.-Y. Liu, and S. Chen, "A glimpse of various pathogenetic mechanisms of diabetic nephropathy," Annual Review of Pathology: Mechanisms of Disease, vol. 6, pp. 395-423, 2011.

[3] M. Brownlee, "The pathobiology of diabetic complications: a unifying mechanism," Diabetes, vol. 54, no. 6, pp. 1615-1625, 2005.

[4] H. S. Lee, "Pathogenic role of TGF-beta in the progression of podocyte diseases," Histology and Histopathology, vol. 26, no. 1, pp. 107-116, 2011.

[5] H. H. Parving, B. Oxenbøll, P. A. Svendsen, J. S. Christiansen, and A. R. Andersen, "Early detection of patients at risk of developing diabetic nephropathy. A longitudinal study of urinary albumin excretion," Acta Endocrinologica (Copenhagen), vol. 100, no. 4, pp. 550-555, 1982.

[6] G. C. Viberti, R. J. Jarrett, U. Mahmud, R. D. Hill, A. Argyropoulos, and $\mathrm{H}$. Keen, "Microalbuminuria as a predictor of clinical nephropathy in insulin-dependent diabetes mellitus," The Lancet, vol. 319, no. 8287, pp. 1430-1432, 1982.

[7] G. Mazzucco, T. Bertani, M. Fortunato et al., "Different patterns of renal damage in type 2 diabetes mellitus: a multicentric study on 393 biopsies," American Journal of Kidney Diseases, vol. 39, no. 4, pp. 713-720, 2002.

[8] K. O. Alsaad and A. M. Herzenberg, "Distinguishing diabetic nephropathy from other causes of glomerulosclerosis: an update," Journal of Clinical Pathology, vol. 60, no. 1, pp. 18-26, 2007.

[9] T. W. C. Tervaert, A. L. Mooyaart, K. Amann et al., "Pathologic classification of diabetic nephropathy," Journal of the American Society of Nephrology, vol. 21, no. 4, pp. 556-563, 2010.

[10] F. C. Brosius III, C. E. Alpers, E. P. Bottinger et al., "Mouse models of diabetic nephropathy," Journal of the American Society of Nephrology, vol. 20, no. 12, pp. 2503-2512, 2009.

[11] D. W. Bowden, C. J. Colicigno, C. D. Langefeld et al., "A genome scan for diabetic nephropathy in African Americans," Kidney International, vol. 66, no. 4, pp. 1517-1526, 2004.
[12] I. Vardarli, L. J. Baier, R. L. Hanson et al., "Gene for susceptibility to diabetic nephropathy in type 2 diabetes maps to $18 \mathrm{q} 22.3-23$," Kidney International, vol. 62, no. 6, pp. 2176-2183, 2002.

[13] N. D. Palmer, M. C. Y. Ng, P. J. Hicks et al., "Evaluation of candidate nephropathy susceptibility genes in a genome-wide association study of African American diabetic kidney disease," PLoS ONE, vol. 9, no. 2, Article ID e88273, 2014.

[14] C. W. McDonough, N. D. Palmer, P. J. Hicks et al., "A genomewide association study for diabetic nephropathy genes in African Americans," Kidney International, vol. 79, no. 5, pp. 563-572, 2011.

[15] B. Janssen, D. Hohenadel, P. Brinkkoetter et al., "Carnosine as a protective factor in diabetic nephropathy: association with a leucine repeat of the carnosinase gene CNDP1," Diabetes, vol. 54, no. 8, pp. 2320-2327, 2005.

[16] A. L. Mooyaart, E. J. J. Valk, L. A. Van Es et al., "Genetic associations in diabetic nephropathy: a meta-analysis," Diabetologia, vol. 54, no. 3, pp. 544-553, 2011.

[17] J.-M. Zhu, B. Wang, J. Li et al., "D18S880 microsatellite polymorphism of carnosinase gene and diabetic nephropathy: a metaanalysis," Genetic Testing and Molecular Biomarkers, vol. 17, no. 4, pp. 289-294, 2013.

[18] M. G. Pezzolesi, P. Katavetin, M. Kure et al., "Confirmation of genetic associations at ELMO1 in the GoKinD collection supports its role as a susceptibility gene in diabetic nephropathy," Diabetes, vol. 58, no. 11, pp. 2698-2702, 2009.

[19] A. Shimazaki, Y. Kawamura, A. Kanazawa et al., "Genetic variations in the gene encoding ELMO1 are associated with susceptibility to diabetic nephropathy," Diabetes, vol. 54 , no. 4 , pp. 1171-1178, 2005.

[20] B. I. Freedman, C. D. Langefeld, L. Lu et al., "Differential effects of MYH9 and APOL1 risk variants on FRMD3 association with diabetic ESRD in African Americans," PLoS Genetics, vol. 7, no. 6, Article ID e1002150, 2011.

[21] M. G. Pezzolesi, J. Jeong, A. M. Smiles et al., "Family-based association analysis confirms the role of the chromosome 9q21.32 locus in the susceptibility of diabetic nephropathy," PLoS ONE, vol. 8, no. 3, Article ID e60301, 2013.

[22] R. L. Hanson, D. W. Craig, M. P. Millis et al., "Identification of PVT1 as a candidate gene for end-stage renal disease in type 2 diabetes using a pooling-based genome-wide single nucleotide polymorphism association study," Diabetes, vol. 56, no. 4, pp. 975-983, 2007.

[23] M. P. Millis, D. Bowen, C. Kingsley, R. M. Watanabe, and J. $\mathrm{K}$. Wolford, "Variants in the plasmacytoma variant translocation gene (PVT1) are associated with end-stage renal disease attributed to type 1 diabetes," Diabetes, vol. 56, no. 12, pp. 30273032, 2007.

[24] M. Herman-Edelstein, P. Scherzer, A. Tobar, M. Levi, and U. Gafter, "Altered renal lipid metabolism and renal lipid accumulation in human diabetic nephropathy," Journal of Lipid Research, vol. 55, no. 3, pp. 561-572, 2014.

[25] T. Konoshita, S. Wakahara, S. Mizuno et al., "Tissue gene expression of renin-angiotensin system in human type 2 diabetic nephropathy," Diabetes Care, vol. 29, no. 4, pp. 848-852, 2006.

[26] H. N. Reich, G. Y. Oudit, J. M. Penninger, J. W. Scholey, and A. M. Herzenberg, "Decreased glomerular and tubular expression of ACE2 in patients with type 2 diabetes and kidney disease," Kidney International, vol. 74, no. 12, pp. 1610-1616, 2008.

[27] M. Zheng, L.-L. Lv, Y.-H. Cao et al., "A pilot trial assessing urinary gene expression profiling with an mRNA array for 
diabetic nephropathy," PLoS ONE, vol. 7, no. 5, Article ID e34824, 2012.

[28] G. Wang, F. M.-M. Lai, K.-B. Lai, K.-M. Chow, K.-T. P. Li, and C.-C. Szeto, "Messenger RNA expression of podocyteassociated molecules in the urinary sediment of patients with diabetic nephropathy," Nephron-Clinical Practice, vol. 106, no. 4, pp. c169-c179, 2007.

[29] M. Zheng, L.-L. Lv, J. Ni et al., "Urinary podocyte-associated mRNA profile in various stages of diabetic nephropathy," PLoS ONE, vol. 6, no. 5, Article ID e20431, 2011.

[30] H. Sun, J.-M. Zheng, S. Chen, C.-H. Zeng, Z.-H. Liu, and L.S. Li, "Enhanced expression of ANGPTL2 in the microvascular lesions of diabetic glomerulopathy," Nephron-Experimental Nephrology, vol. 105, no. 4, pp. el17-e123, 2007.

[31] E. P. Brennan, M. J. Morine, D. W. Walsh et al., "Next-generation sequencing identifies TGF-betal-associated gene expression profiles in renal epithelial cells reiterated in human diabetic nephropathy," Biochimica et Biophysica Acta-Molecular Basis of Disease, vol. 1822, no. 4, pp. 589-599, 2012.

[32] H. J. Baelde, M. Eikmans, P. P. Doran, D. W. P. Lappin, E. De Heer, and J. A. Bruijn, "Gene expression profiling in glomeruli from human kidneys with diabetic nephropathy," American Journal of Kidney Diseases, vol. 43, no. 4, pp. 636-650, 2004.

[33] L. Fiorentino, M. Cavalera, S. Menini et al., "Loss of TIMP3 underlies diabetic nephropathy via FoxO1/STAT1 interplay," EMBO Molecular Medicine, vol. 5, no. 3, pp. 441-455, 2013.

[34] X. Wang, J. Liu, J. Zhen et al., "Histone deacetylase 4 selectively contributes to podocyte injury in diabetic nephropathy," Kidney International, vol. 86, no. 4, pp. 712-725, 2014.

[35] H. Schmid, A. Boucherot, Y. Yasuda et al., "Modular activation of nuclear factor-kappaB transcriptional programs in human diabetic nephropathy," Diabetes, vol. 55, no. 11, pp. 2993-3003, 2006.

[36] P. Fiorina, A. Vergani, R. Bassi et al., "Role of podocyte B71 in diabetic nephropathy," Journal of the American Society of Nephrology, vol. 25, no. 7, pp. 1415-1429, 2014.

[37] K. I. Woroniecka, A. S. D. Park, D. Mohtat, D. B. Thomas, J. M. Pullman, and K. Susztak, "Transcriptome analysis of human diabetic kidney disease," Diabetes, vol. 60, no. 9, pp. 2354-2369, 2011.

[38] D. Verzola, L. Cappuccino, E. D’Amato et al., "Enhanced glomerular Toll-like receptor 4 expression and signaling in patients with type 2 diabetic nephropathy and microalbuminuria," Kidney International, vol. 86, no. 6, pp. 1229-1243, 2014.

[39] M. T. Lindenmeyer, M. Kretzler, A. Boucherot et al., "Interstitial vascular rarefaction and reduced VEGF-A expression in human diabetic nephropathy," Journal of the American Society of Nephrology, vol. 18, no. 6, pp. 1765-1776, 2007.

[40] J. Gerth, C. D. Cohen, U. Hopfer et al., "Collagen type VIII expression in human diabetic nephropathy," European Journal of Clinical Investigation, vol. 37, no. 10, pp. 767-773, 2007.

[41] H. J. Baelde, M. Eikmans, D. W. P. Lappin et al., "Reduction of VEGF-A and CTGF expression in diabetic nephropathy is associated with podocyte loss," Kidney International, vol. 71, no. 7, pp. 637-645, 2007.

[42] H. Kato, A. Gruenwald, J. H. Suh et al., "Wnt/ $\beta$-catenin pathway in podocytes integrates cell adhesion, differentiation, and survival," The Journal of Biological Chemistry, vol. 286, no. 29, pp. 26003-26015, 2011.

[43] R. Vasko, M. Koziolek, M. Ikehata et al., "Role of basic fibroblast growth factor (FGF-2) in diabetic nephropathy and mechanisms of its induction by hyperglycemia in human renal fibroblasts," The American Journal of Physiology-Renal Physiology, vol. 296, no. 6, pp. F1452-F1463, 2009.

[44] Y. Yamaguchi, M. Iwano, D. Suzuki et al., "Epithelialmesenchymal transition as a potential explanation for podocyte depletion in diabetic nephropathy," American Journal of Kidney Diseases, vol. 54, no. 4, pp. 653-664, 2009.

[45] V. Dolan, M. Murphy, D. Sadlier et al., "Expression of gremlin, a bone morphogenetic protein antagonist, in human diabetic nephropathy," American Journal of Kidney Diseases, vol. 45, no. 6, pp. 1034-1039, 2005.

[46] D. W. Walsh, S. A. Roxburgh, P. McGettigan et al., "Coregulation of Gremlin and Notch signalling in diabetic nephropathy," Biochimica et Biophysica Acta-Molecular Basis of Disease, vol. 1782, no. 1, pp. 10-21, 2008.

[47] M. T. Lindenmeyer, M. P. Rastaldi, M. Ikehata et al., "Proteinuria and hyperglycemia induce endoplasmic reticulum stress," Journal of the American Society of Nephrology, vol. 19, no. 11, pp. 2225-2236, 2008.

[48] M. Murphy, N. G. Docherty, B. Griffin et al., "IHG-1 amplifies TGF-betal signaling and is increased in renal fibrosis," Journal of the American Society of Nephrology, vol. 19, no. 9, pp. 1672$1680,2008$.

[49] M. B. Hookham, H. C. O’Donovan, R. H. Church et al., "Insulin receptor substrate-2 is expressed in kidney epithelium and upregulated in diabetic nephropathy," FEBS Journal, vol. 280, no. 14, pp. 3232-3243, 2013.

[50] C. C. Berthier, H. Zhang, M. Schin et al., "Enhanced expression of janus kinase-signal transducer and activator of transcription pathway members in human diabetic nephropathy," Diabetes, vol. 58, no. 2, pp. 469-477, 2009.

[51] C. D. Cohen, M. T. Lindenmeyer, F. Eichinger et al., "Improved elucidation of biological processes linked to diabetic nephropathy by single probe-based microarray data analysis," PLOS ONE, vol. 3, no. 8, Article ID e2937, 2008.

[52] T. Kuwabara, K. Mori, M. Kasahara et al., "Predictive significance of kidney myeloid-related protein 8 expression in patients with obesity- or type 2 diabetes-associated kidney diseases," PLoS ONE, vol. 9, no. 2, Article ID e88942, 2014.

[53] C.-C. Szeto, K.-B. Lai, K.-M. Chow et al., "Messenger RNA expression of glomerular podocyte markers in the urinary sediment of acquired proteinuric diseases," Clinica Chimica Acta, vol. 361, no. 1-2, pp. 182-190, 2005.

[54] M. Toyoda, D. Suzuki, T. Umezono et al., "Expression of human nephrin mRNA in diabetic nephropathy," Nephrology Dialysis Transplantation, vol. 19, no. 2, pp. 380-385, 2004.

[55] T. Bondeva, C. Rüster, S. Franke et al., "Advanced glycation end-products suppress neuropilin-1 expression in podocytes," Kidney International, vol. 75, no. 6, pp. 605-616, 2009.

[56] C. Lorz, A. Benito-Martín, A. Boucherot et al., "The death ligand TRAIL in diabetic nephropathy," Journal of the American Society of Nephrology, vol. 19, no. 5, pp. 904-914, 2008.

[57] R. G. Langham, D. J. Kelly, J. Maguire, J. P. Dowling, R. E. Gilbert, and N. M. Thomson, "Over-expression of platelet-derived growth factor in human diabetic nephropathy," Nephrology Dialysis Transplantation, vol. 18, no. 7, pp. 1392-1396, 2003.

[58] I. Tossidou, B. Teng, J. Menne et al., "Podocytic PKC-alpha is regulated in murine and human diabetes and mediates nephrin endocytosis," PLoS ONE, vol. 5, no. 4, Article ID e10185, 2010. 
[59] R. G. Langham, D. J. Kelly, R. M. Gow et al., "Increased renal gene transcription of protein kinase C-beta in human diabetic nephropathy: relationship to long-term glycaemic control," Diabetologia, vol. 51, no. 4, pp. 668-674, 2008.

[60] M. T. Lindenmeyer, F. Eichinger, K. Sen et al., "Systematic analysis of a novel human renal glomerulus-enriched gene expression dataset," PLoS ONE, vol. 5, no. 7, Article ID el1545, 2010.

[61] T. H. Yoo, C. E. Pedigo, J. Guzman et al., "Sphingomyelinaselike phosphodiesterase $3 \mathrm{~b}$ expression levels determine podocyte injury phenotypes in glomerular disease," Journal of the American Society of Nephrology, vol. 26, no. 1, pp. 133-147, 2015.

[62] S. Zhang, Y. Zhang, X. Wei et al., "Expression and regulation of a novel identified TNFAIP8 family is associated with diabetic nephropathy," Biochimica et Biophysica Acta, vol. 1802, no. 11, pp. 1078-1086, 2010.

[63] R. G. Langham, D. J. Kelly, R. M. Gow et al., "Increased expression of urotensin II and urotensin II receptor in human diabetic nephropathy," American Journal of Kidney Diseases, vol. 44, no. 5, pp. 826-831, 2004.

[64] E. Bortoloso, D. Del Prete, M. Dalla Vestra et al., "Quantitave and qualitative changes in vascular endothelial growth factor gene expression in glomeruli of patients with type 2 diabetes," European Journal of Endocrinology, vol. 150, no. 6, pp. 799-807, 2004.

[65] Y. Kanesaki, D. Suzuki, G. Uehara et al., "Vascular endothelial growth factor gene expression is correlated with glomerular neovascularization in human diabetic nephropathy," American Journal of Kidney Diseases, vol. 45, no. 2, pp. 288-294, 2005.

[66] M. L. Alvarez, M. Khosroheidari, E. Eddy, and J. Kiefer, "Role of microRNA 1207-5P and its host gene, the long non-coding RNA Pvtl, as mediators of extracellular matrix accumulation in the kidney: implications for diabetic nephropathy," PLoS ONE, vol. 8, no. 10, Article ID e77468, 2013.

[67] Q. Wang, Y. Wang, A. W. Minto et al., "MicroRNA-377 is upregulated and can lead to increased fibronectin production in diabetic nephropathy," The FASEB Journal, vol. 22, no. 12, pp. 4126-4135, 2008.

[68] F. Barutta, M. Tricarico, A. Corbelli et al., "Urinary exosomal MicroRNAs in incipient diabetic nephropathy," PLOS ONE, vol. 8, no. 11, Article ID e73798, 2013.

[69] Y. Huang, Y. Liu, L. Li et al., "Involvement of inflammationrelated miR-155 and miR-146a in diabetic nephropathy: implications for glomerular endothelial injury," BMC Nephrology, vol. 15, article 142, 2014.

[70] C.-C. Szeto, K. B. Ching-Ha, L. Ka-Bik et al., "Micro-RNA expression in the urinary sediment of patients with chronic kidney diseases," Disease Markers, vol. 33, no. 3, pp. 137-144, 2012.

[71] C. Argyropoulos, K. Wang, S. McClarty et al., "Urinary microRNA profiling in the nephropathy of type 1 diabetes," PLoS ONE, vol. 8, no. 1, Article ID e54662, 2013.

[72] A. Krupa, R. Jenkins, D. DongLuo, A. Lewis, A. Phillips, and D. Fraser, "Loss of microRNA-192 promotes fibrogenesis in diabetic nephropathy," Journal of the American Society of Nephrology, vol. 21, no. 3, pp. 438-447, 2010.

[73] G. Wang, B. C.-H. Kwan, F. M.-M. Lai, K.-M. Chow, P. K.-T. Li, and C.-C. Szeto, "Urinary sediment miRNA levels in adult nephrotic syndrome," Clinica Chimica Acta, vol. 418, pp. 5-11, 2013.
[74] L. Fiorentino, M. Cavalera, M. Mavilio et al., "Regulation of TIMP3 in diabetic nephropathy: a role for microRNAs," Acta Diabetologica, vol. 50, no. 6, pp. 965-969, 2013.

[75] H. Peng, M. Zhong, W. Zhao et al., "Urinary miR-29 correlates with albuminuria and carotid intima-media thickness in type 2 diabetes patients," PLoS ONE, vol. 8, no. 12, Article ID e82607, 2013.

[76] J. Zhou, R. Peng, T. Li et al., "A potentially functional polymorphism in the regulatory region of let-7a-2 is associated with an increased risk for diabetic nephropathy," Gene, vol. 527, no. 2, pp. 456-461, 2013.

[77] J. Geisel, H. Schorr, G. H. Heine et al., "Decreased p66 ${ }^{\text {Shc }}$ promoter methylation in patients with end-stage renal disease," Clinical Chemistry and Laboratory Medicine, vol. 45, no. 12, pp. 1764-1770, 2007.

[78] C. G. Bell, A. E. Teschendorff, V. K. Rakyan, A. P. Maxwell, S. Beck, and D. A. Savage, "Genome-wide DNA methylation analysis for diabetic nephropathy in type 1 diabetes mellitus," BMC Medical Genomics, vol. 3, article 33, 2010.

[79] S. Nakatani, M. Wei, E. Ishimura et al., "Proteome analysis of laser microdissected glomeruli from formalin-fixed paraffin-embedded kidneys of autopsies of diabetic patients: nephronectin is associated with the development of diabetic glomerulosclerosis," Nephrology, Dialysis, Transplantation, vol. 27, no. 5, pp. 1889-1897, 2012.

[80] A. A. Satoskar, J. P. Shapiro, C. N. Bott et al., "Characterization of glomerular diseases using proteomic analysis of laser capture microdissected glomeruli," Modern Pathology, vol. 25, no. 5, pp. 709-721, 2012.

[81] S. S. Roscioni, D. De Zeeuw, M. E. Hellemons et al., "A urinary peptide biomarker set predicts worsening of albuminuria in type 2 diabetes mellitus," Diabetologia, vol. 56, no. 2, pp. 259267, 2013.

[82] D. Schlatzer, D. M. Maahs, M. R. Chance et al., "Novel urinary protein biomarkers predicting the development of microalbuminuria and renal function decline in type 1 diabetes," Diabetes Care, vol. 35, no. 3, pp. 549-555, 2012.

[83] J. Jin, Y. H. Ku, Y. Kim et al., "Differential proteome profiling using iTRAQ in microalbuminuric and normoalbuminuric type 2 diabetic patients," Experimental Diabetes Research, vol. 2012, Article ID 168602, 31 pages, 2012.

[84] H. Dihazi, G. A. Müller, S. Lindner et al., "Characterization of diabetic nephropathy by urinary proteomic analysis: identification of a processed ubiquitin form as a differentially excreted protein in diabetic nephropathy patients," Clinical Chemistry, vol. 53, no. 9, pp. 1636-1645, 2007.

[85] M. Papale, S. Di Paolo, R. Magistroni et al., "Urine proteome analysis may allow noninvasive differential diagnosis of diabetic nephropathy," Diabetes Care, vol. 33, no. 11, pp. 2409-2415, 2010.

[86] I. Zubiri, M. Posada-Ayala, A. Sanz-Maroto et al., "Diabetic nephropathy induces changes in the proteome of human urinary exosomes as revealed by label-free comparative analysis," Journal of Proteomics, vol. 96, pp. 92-102, 2014.

[87] J.-M. Ahn, B.-G. Kim, M.-H. Yu, I.-K. Lee, and J.-Y. Cho, "Identification of diabetic nephropathy-selective proteins in human plasma by multi-lectin affinity chromatography and LCMS/MS," Proteomics-Clinical Applications, vol. 4, no. 6-7, pp. 644-653, 2010

[88] M.-R. Kim, S.-A. Yu, M.-Y. Kim, K. M. Choi, and C.-W. Kim, "Analysis of glycated serum proteins in type 2 diabetes patients with nephropathy," Biotechnology and Bioprocess Engineering, vol. 19, no. 1, pp. 83-92, 2014. 
[89] E.-H. Cho, M.-R. Kim, H.-J. Kim et al., "The discovery of biomarkers for type 2 diabetic nephropathy by serum proteome analysis," Proteomics-Clinical Applications, vol. 1, no. 4, pp. 352-361, 2007.

[90] K. Sharma, B. Karl, A. V. Mathew et al., "Metabolomics reveals signature of mitochondrial dysfunction in diabetic kidney disease," Journal of the American Society of Nephrology, vol. 24, no. 11, pp. 1901-1912, 2013.

[91] M. J. Pena, H. J. L. Heerspink, M. E. Hellemons et al., "Urine and plasma metabolites predict the development of diabetic nephropathy in individuals with type 2 diabetes mellitus," Diabetic Medicine, vol. 31, no. 9, pp. 1138-1147, 2014.

[92] F. M. van der Kloet, F. W. A. Tempels, N. Ismail et al., "Discovery of early-stage biomarkers for diabetic kidney disease using msbased metabolomics (FinnDiane study)," Metabolomics, vol. 8, no. 1, pp. 109-119, 2012.

[93] V. G. Marrachelli, D. Monleon, P. Rentero et al., "Genomic and metabolomic profile associated to microalbuminuria," PLoS ONE, vol. 9, no. 6, Article ID e98227, 2014.

[94] A. Hirayama, E. Nakashima, M. Sugimoto et al., "Metabolic profiling reveals new serum biomarkers for differentiating diabetic nephropathy," Analytical and Bioanalytical Chemistry, vol. 404, no. 10, pp. 3101-3109, 2012.

[95] J. Zhang, L. Yan, W. Chen et al., "Metabonomics research of diabetic nephropathy and type 2 diabetes mellitus based on UPLC-oaTOF-MS system," Analytica Chimica Acta, vol. 650, no. 1, pp. 16-22, 2009.

[96] J.-F. Xia, Q.-L. Liang, X.-P. Liang et al., "Ultraviolet and tandem mass spectrometry for simultaneous quantification of 21 pivotal metabolites in plasma from patients with diabetic nephropathy," Journal of Chromatography B: Analytical Technologies in the Biomedical and Life Sciences, vol. 877, no. 20-21, pp. 1930-1936, 2009.

[97] C. Zhu, Q.-L. Liang, P. Hu, Y.-M. Wang, and G.-A. Luo, "Phospholipidomic identification of potential plasma biomarkers associated with type 2 diabetes mellitus and diabetic nephropathy," Talanta, vol. 85, no. 4, pp. 1711-1720, 2011.

[98] L.-D. Han, J.-F. Xia, Q.-L. Liang et al., "Plasma esterified and non-esterified fatty acids metabolic profiling using gas chromatography-mass spectrometry and its application in the study of diabetic mellitus and diabetic nephropathy," Analytica Chimica Acta, vol. 689, no. 1, pp. 85-91, 2011.

[99] E. R. Seaquist, F. C. Goetz, S. Rich, and J. Barbosa, "Familial clustering of diabetic kidney disease," The New England Journal of Medicine, vol. 320, no. 18, pp. 1161-1165, 1989.

[100] H. Kramer, W. Palmas, B. Kestenbaum et al., "Chronic kidney disease prevalence estimates among racial/ethnic groups: the multi-ethnic study of atherosclerosis," Clinical Journal of the American Society of Nephrology, vol. 3, no. 5, pp. 1391-1397, 2008.

[101] A. R. Hipkiss, J. E. Preston, D. T. M. Himsworth et al., "Pluripotent protective effects of carnosine, a naturally occurring dipeptide," Annals of the New York Academy of Sciences, vol. 854, no. 1, pp. 37-53, 1998.

[102] J. Makuc and D. Petrovic, "Diabetic nephropathy in type 2 diabetes: MPO T-764C genotype is associated with oxidative stress," Central European Journal of Biology, vol. 7, no. 6, pp. 964-972, 2012.

[103] A. Shimazaki, Y. Tanaka, T. Shinosaki et al., "ELMO1 increases expression of extracellular matrix proteins and inhibits cell adhesion to ECMs," Kidney International, vol. 70, no. 10, pp. 1769-1776, 2006.
[104] P. W. Mueller, J. J. Rogus, P. A. Cleary et al., "Genetics of Kidneys in Diabetes (GoKinD) study: a genetics collection available for identifying genetic susceptibility factors for diabetic nephropathy in type 1 diabetes," Journal of the American Society of Nephrology, vol. 17, no. 7, pp. 1782-1790, 2006.

[105] M. G. Pezzolesi, G. D. Poznik, J. C. Mychaleckyj et al., "Genomewide association scan for diabetic nephropathy susceptibility genes in type 1 diabetes," Diabetes, vol. 58, no. 6, pp. 1403-1410, 2009.

[106] P. P. H. De Bruyn, S. Michelson, and R. P. Becker, "Endocytosis, transfer tubules, and lysosomal activity in myeloid sinusoidal endothelium," Journal of Ultrastructure Research, vol. 53, no. 2, pp. 133-151, 1975.

[107] M. Ha and V. N. Kim, "Regulation of microRNA biogenesis," Nature Reviews Molecular Cell Biology, vol. 15, no. 8, pp. 509524, 2014.

[108] M. Inui, G. Martello, and S. Piccolo, "MicroRNA control of signal transduction," Nature Reviews Molecular Cell Biology, vol. 11, no. 4, pp. 252-263, 2010.

[109] M. Kato, J. Zhang, M. Wang et al., "MicroRNA-192 in diabetic kidney glomeruli and its function in TGF- $\beta$-induced collagen expression via inhibition of E-box repressors," Proceedings of the National Academy of Sciences of the United States of America, vol. 104, no. 9, pp. 3432-3437, 2007.

[110] A. Zarjou, S. Yang, E. Abraham, A. Agarwal, and G. Liu, "Identification of a microRNA signature in renal fibrosis: role of miR-21," American Journal of Physiology-Renal Physiology, vol. 301, no. 4, pp. F793-F801, 2011.

[111] A. A. Eddy, "The TGF-beta route to renal fibrosis is not linear: the miR-21 viaduct," Journal of the American Society of Nephrology, vol. 22, no. 9, pp. 1573-1575, 2011.

[112] M. L. Alvarez and J. K. DiStefano, "Functional characterization of the plasmacytoma variant translocation 1 gene (PVT1) in diabetic nephropathy," PLoS ONE, vol. 6, no. 4, Article ID e18671, 2011.

[113] L. Pirola, A. Balcerczyk, J. Okabe, and A. El-Osta, "Epigenetic phenomena linked to diabetic complications," Nature Reviews Endocrinology, vol. 6, no. 12, pp. 665-675, 2010.

[114] G. G. Camici, M. Schiavoni, P. Francia et al., "Genetic deletion of $\mathrm{p} 66^{\text {Shc }}$ adaptor protein prevents hyperglycemia-induced endothelial dysfunction and oxidative stress," Proceedings of the National Academy of Sciences of the United States of America, vol. 104, no. 12, pp. 5217-5222, 2007.

[115] C. Sapienza, J. Lee, J. Powell et al., "DNA methylation profling identifes epigenetic differences between diabetes patients with ESRD and diabetes patients without nephropathy," Epigenetics, vol. 6, no. 1, pp. 20-28, 2011.

[116] K. Hasegawa, S. Wakino, P. Simic et al., "Renal tubular Sirt1 attenuates diabetic albuminuria by epigenetically suppressing claudin-1 overexpression in podocytes," Nature Medicine, vol. 19, no. 11, pp. 1496-1504, 2013.

[117] M. A. Reddy, P. Sumanth, L. Lanting et al., "Losartan reverses permissive epigenetic changes in renal glomeruli of diabetic db/db mice," Kidney International, vol. 85, no. 2, pp. 362-373, 2014.

[118] M. Papale, S. Di Paolo, G. Vocino, M. T. Rocchetti, and L. Gesualdo, "Proteomics and diabetic nephropathy: what have we learned from a decade of clinical proteomics studies?" Journal of Nephrology, vol. 27, no. 3, pp. 221-228, 2014.

[119] B. Najafian, C. E. Alpers, and A. B. Fogo, "Pathology of human diabetic nephropathy," Contributions to Nephrology, vol. 170, pp. 36-47, 2011. 
[120] L. D. Ralton and G. I. Murray, "The use of formalin fixed wax embedded tissue for proteomic analysis," Journal of Clinical Pathology, vol. 64, no. 4, pp. 297-302, 2011.

[121] M. R. Emmert-Buck, R. F. Bonner, P. D. Smith et al., "Laser capture microdissection," Science, vol. 274, no. 5289, pp. 9981001, 1996.

[122] A. Blutke, "Opening a treasure chest: glomerular proteome analyses of formalin-fixed paraffin-embedded kidney tissue in the investigation of diabetic nephropathy," Nephrology, Dialysis, Transplantation, vol. 27, no. 5, pp. 1695-1698, 2012.

[123] J. M. Linton, G. R. Martin, and L. F. Reichardt, "The ECM protein nephronectin promotes kidney development via integrin $\alpha 8 \beta 1$-mediated stimulation of Gdnf expression," Development, vol. 134, no. 13, pp. 2501-2509, 2007.

[124] K. Rossing, H. Mischak, M. Dakna et al., "Urinary proteomics in diabetes and CKD," Journal of the American Society of Nephrology, vol. 19, no. 7, pp. 1283-1290, 2008.

[125] A. Alkhalaff, P. Zürbig, S. J. L. Bakker et al., "Multicentric validation of proteomic biomarkers in urine specific for diabetic nephropathy," PLoS ONE, vol. 5, no. 10, Article ID e13421, 2010.

[126] P. Zürbig, G. Jerums, P. Hovind et al., "Urinary proteomics for early diagnosis in diabetic nephropathy," Diabetes, vol. 61, no. 12, pp. 3304-3313, 2012.

[127] D. M. Good, P. Zürbig, A. Argilés et al., "Naturally occurring human urinary peptides for use in diagnosis of chronic kidney disease," Molecular \& Cellular Proteomics, vol. 9, no. 11, pp. 2424-2437, 2010.

[128] T. Pisitkun, R.-F. Shen, and M. A. Knepper, "Identification and proteomic profiling of exosomes in human urine," Proceedings of the National Academy of Sciences of the United States of America, vol. 101, no. 36, pp. 13368-13373, 2004.

[129] P. A. Gonzales, T. Pisitkun, J. D. Hoffert et al., "Large-scale proteomics and phosphoproteomics of urinary exosomes," Journal of the American Society of Nephrology, vol. 20, no. 2, pp. 363-379, 2009.

[130] A. Vivekanandan-Giri, J. L. Slocum, C. L. Buller et al., "Urine glycoprotein profile reveals novel markers for chronic kidney disease," International Journal of Proteomics, vol. 2011, Article ID 214715, 18 pages, 2011.

[131] X. Fang and W.-W. Zhang, "Affinity separation and enrichment methods in proteomic analysis," Journal of Proteomics, vol. 71, no. 3, pp. 284-303, 2008.

[132] H.-J. Kim, E.-H. Cho, J.-H. Yoo et al., "Proteome analysis of serum from type 2 diabetics with nephropathy," Journal of Proteome Research, vol. 6, no. 2, pp. 735-743, 2007.

[133] H. G. Hansen, J. Overgaard, M. Lajer et al., "Finding diabetic nephropathy biomarkers in the plasma peptidome by highthroughput magnetic bead processing and MALDI-TOF-MS analysis," Proteomics-Clinical Applications, vol. 4, no. 8-9, pp. 697-705, 2010.

[134] T. D. Veenstra, "Metabolomics: the final frontier?" Genome Medicine, vol. 4, no. 4, article 40, 2012.

[135] J. R. Bain, R. D. Stevens, B. R. Wenner, O. Ilkayeva, D. M. Muoio, and C. B. Newgard, "Metabolomics applied to diabetes research: moving from information to knowledge," Diabetes, vol. 58, no. 11, pp. 2429-2443, 2009.

[136] S. J. Mihalik, B. H. Goodpaster, D. E. Kelley et al., "Increased levels of plasma acylcarnitines in obesity and type 2 diabetes and identification of a marker of glucolipotoxicity," Obesity, vol. 18, no. 9, pp. 1695-1700, 2010.
[137] D. E. Kelley, J. He, E. V. Menshikova, and V. B. Ritov, "Dysfunction of mitochondria in human skeletal muscle in type 2 diabetes," Diabetes, vol. 51, no. 10, pp. 2944-2950, 2002.

[138] K. C. B. Tan, S. W. M. Shiu, and Y. Wong, "Plasma phospholipid transfer protein activity and small, dense LDL in type 2 diabetes mellitus," European Journal of Clinical Investigation, vol. 33, no. 4, pp. 301-306, 2003.

[139] L.-Q. Pang, Q.-L. Liang, Y.-M. Wang, L. Ping, and G.-A. Luo, "Simultaneous determination and quantification of seven major phospholipid classes in human blood using normalphase liquid chromatography coupled with electrospray mass spectrometry and the application in diabetes nephropathy," Journal of Chromatography B: Analytical Technologies in the Biomedical and Life Sciences, vol. 869, no. 1-2, pp. 118-125, 2008.

[140] J. M. Weinberg, "Lipotoxicity," Kidney International, vol. 70, no. 9, pp. 1560-1566, 2006. 


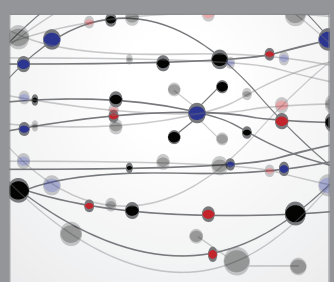

The Scientific World Journal
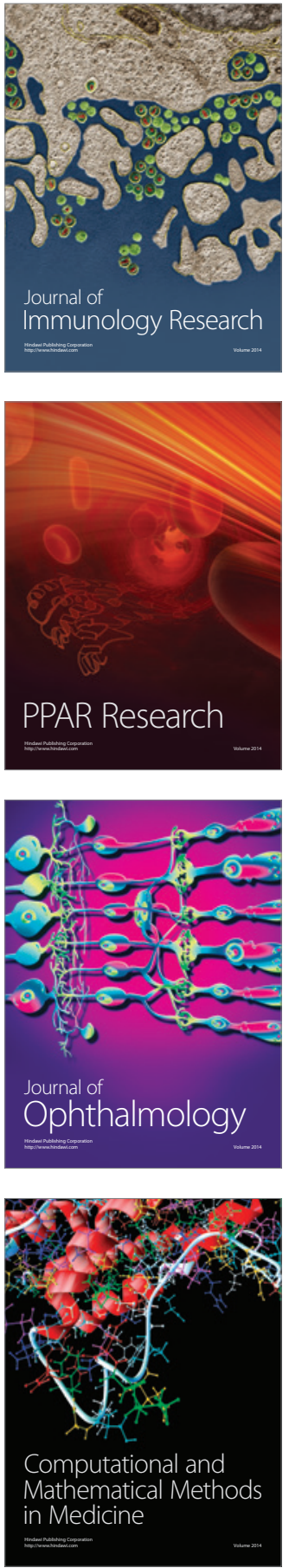

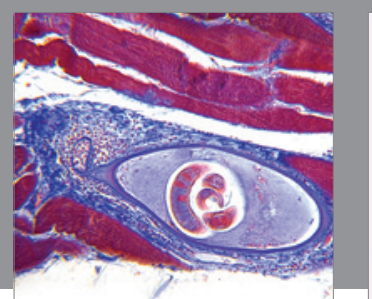

Gastroenterology Research and Practice

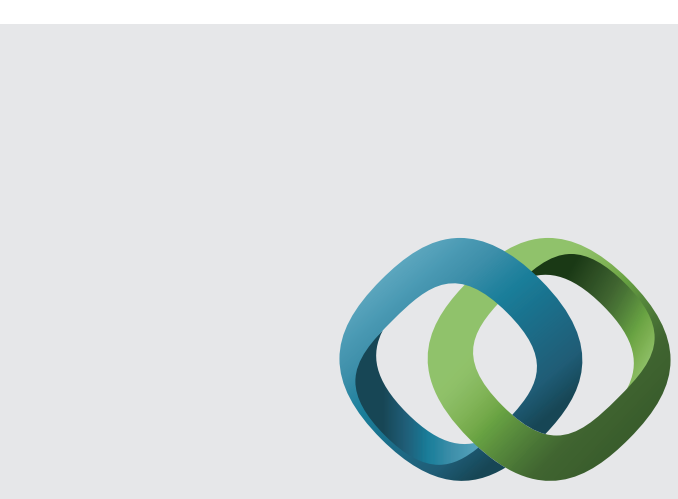

\section{Hindawi}

Submit your manuscripts at

http://www.hindawi.com
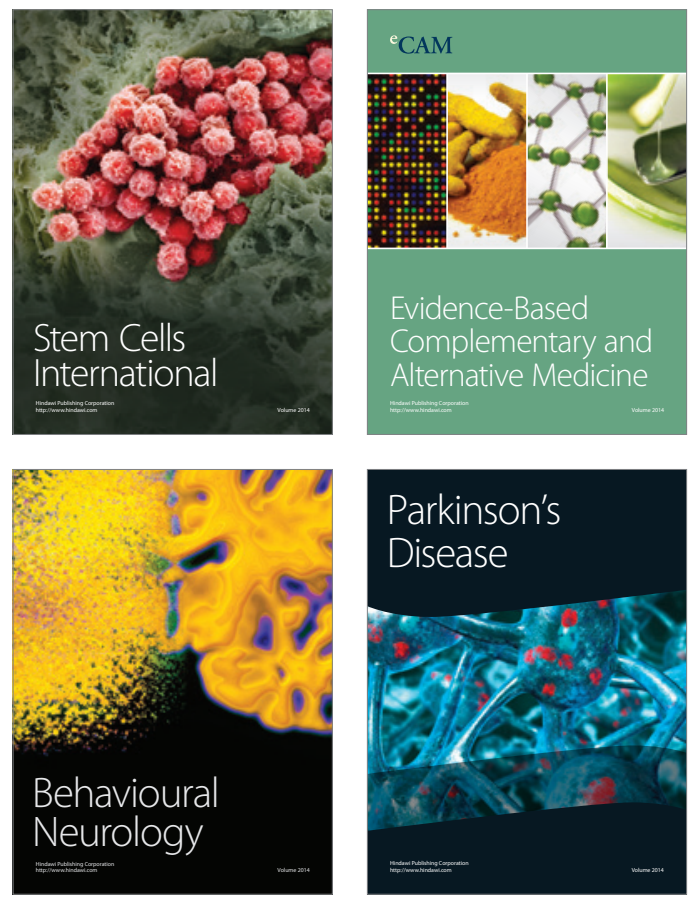
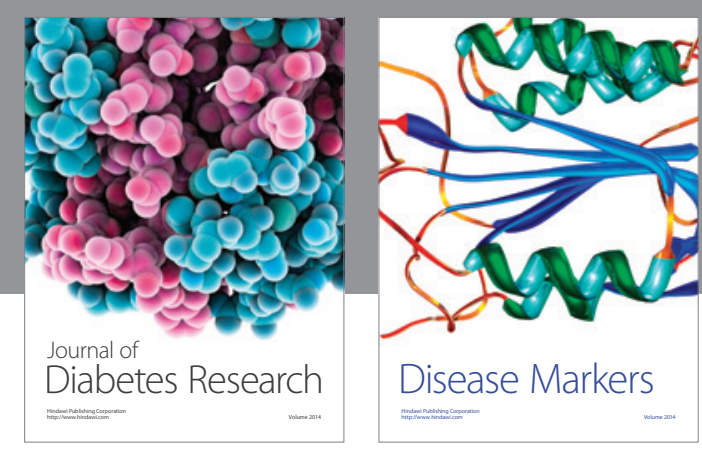

Disease Markers
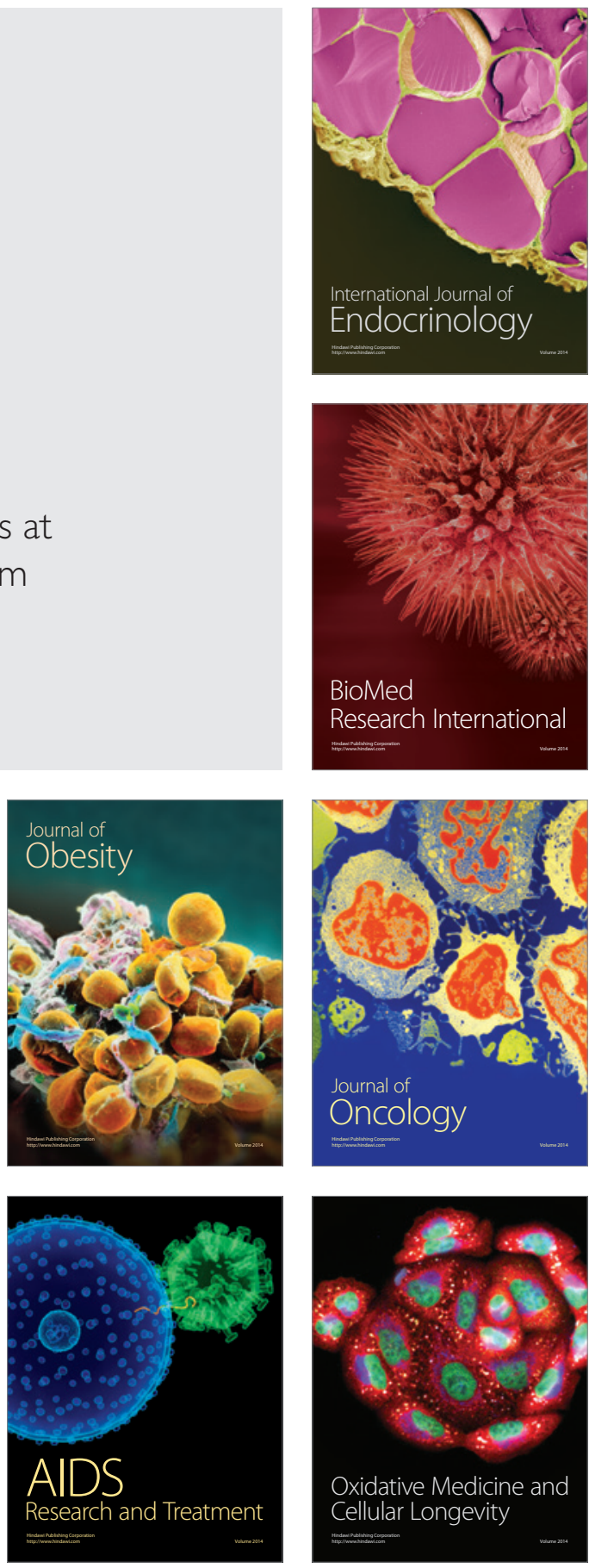